ISSN 1996-1944

www.mdpi.com/journal/materials

Review

\title{
The Electronic Structure and Secondary Pyroelectric Properties of Lithium Tetraborate
}

\section{Volodymyr.T. Adamiv ${ }^{1}$, Yaroslav.V. Burak ${ }^{1}$, David. J. Wooten ${ }^{2}$, John McClory ${ }^{2}$, James} Petrosky $^{2}$, Ihor Ketsman ${ }^{3}$, Jie Xiao ${ }^{3}$, Yaroslav B. Losovyj ${ }^{3,4}$ and Peter A. Dowben ${ }^{3, *}$

1 Institute of Physical Optics, 23 Dragomanov Street, Lviv 79005, Ukraine;

E-Mails: adamiv@ifo.lviv.ua (V.T.A.); burak@ifo.lviv.ua (Y.V.B.)

2 Air Force Institute of Technology, 2950 Hobson Way, Wright Patterson Air Force Base, OH 45433-7765, USA; E-Mails: tdjwooten@ gmail.com (D.J.W.); John.Mcclory@afit.edu (J.M.); James.Petrosky@afit.edu (J.P.)

3 Deptment of Physics and Astronomy and the Nebraska Center for Materials and Nanoscience, Theodore Jorgensen Hall, 855 North 16th Street, University of Nebraska-Lincoln, Lincoln, NE 68588-0299 , USA; E-Mails: iketsman@unlserve.unl.edu (I.K.);

Jie.Xiao@chemie.uni-erlangen.de (J.X.)

4 J. Bennett Johnston Sr. Center for Advanced Microstructures and Devices, Louisiana State University, 6980 Jefferson Highway, Baton Rouge, LA 70806, USA;

E-Mail: ylosovyj@1su.edu (Y.B.L.)

* Author to whom correspondence should be addressed; E-Mail: pdowben@unl.edu; Tel.: +1-402-472-9838; Fax: +1-402-472-6148.

Received: 26 July 2010 / Accepted: 19 August 2010 /

Published: 1 September 2010

Abstract: We review the pyroelectric properties and electronic structure of $\mathrm{Li}_{2} \mathrm{~B}_{4} \mathrm{O}_{7}(110)$ and $\mathrm{Li}_{2} \mathrm{~B}_{4} \mathrm{O}_{7}(100)$ surfaces. There is evidence for a pyroelectric current along the [110] direction of stoichiometric $\mathrm{Li}_{2} \mathrm{~B}_{4} \mathrm{O}_{7}$ so that the pyroelectric coefficient is nonzero but roughly $10^{3}$ smaller than along the [001] direction of spontaneous polarization. Abrupt decreases in the pyroelectric coefficient along the [110] direction can be correlated with anomalies in the elastic stiffness $C_{33}^{D}$ contributing to the concept that the pyroelectric coefficient is not simply a vector but has qualities of a tensor, as expected. The time dependent surface photovoltaic charging suggests that surface charging is dependent on crystal orientation and doping, as well as temperature. 
Keywords: oxide pyroelectric; band structure of insulators; surface states; secondary pyroelectric effects; lithium tetraborate

\section{Introduction}

The study of pyroelectricity has a long and rich history [1], but there are good reasons to suspect that the general models of pyroelectricity tend to be simplistic. Pyroelectricity is usually measured as a current that occurs with changing temperature along the direction of spontaneous polarization [1-4]. It is also important to note that all pyroelectric materials are piezoelectric, because the necessary spontaneous polarization only occurs in materials with a unique polar axis [2]. For a piezoelectric material we expect the charge density $\mathrm{D}_{\mathrm{i}}$ to be related to the stress $X_{\mathrm{jk}}$ by [2]:

$$
\mathrm{D}_{\mathrm{i}}=d_{\mathrm{ijk}} X_{\mathrm{jk}}
$$

where the piezoelectic coefficients, $d_{\mathrm{ijk}}$, form a third rank tensor. We should be able to alter the surface charge density, $D_{i}$, by applying an electric field, as the strain is related to the applied electric field $\underline{\mathbf{E}}$ by:

$$
x_{\mathrm{ij}}=d_{\mathrm{ijk}} \underline{\mathrm{E}}_{\mathrm{k}}
$$

with the stress related to strain, as described by Hooke's law. The pyroelectric effect should, in fact, be a tensor because the surface charge density $D_{i}$, induced by a change in temperature $T$, is also related to the change in static polarization $P_{\mathrm{S}, \mathrm{i}}$, which in turn is related to the pyroelectric coefficient $p_{\mathrm{i}}$ :

$$
\mathrm{D}_{\mathrm{i}}=\Delta P_{\mathrm{S}, \mathrm{i}}=\frac{d P_{\mathrm{S}, \mathrm{i}}}{d \mathrm{~T}} \Delta \mathrm{T}=p_{i} \Delta \mathrm{T}
$$

From equations (1) and (2), with changes in temperature, there is an expected anisotropy of the electric constants and the resulting "stress" with temperature, particularly in a noncubic pyroelectric crystal. This implied tensor character makes equation (3), relating the surface charge density, $\mathrm{D}_{\mathrm{i}}$, to the pyroelectric coefficients $p_{\mathrm{i}}$, over-simplistic. Although the pyroelectric coefficient is generally treated as a vector [2,3], there is implied tensor character present. This tensor character, higher than a first order, is due to the coupling to the stress-strain tensor and the accompanying tensor character of the piezoelectric effect. Indeed, it is recognized that there is a secondary pyroelectric effect that can occur if the pyroelectric crystal is allowed to deform along directions other than the polar direction [2], as has now been conclusively demonstrated [5] for lithium tetraborate $\left(\mathrm{Li}_{2} \mathrm{~B}_{4} \mathrm{O}_{7}\right)$. This is consistent with prior optical studies, which have provided some indications of an off-axis pyroelectric effect along crystal directions orthogonal to the polar axis of some translucent pyroelectric crystals [6].

This demonstration [5] of off-axis (secondary) pyroelectricity is expected and can be studied not only by conventional thermocurrent measurements, but by changes in the surface charging seen in photoemission. These latter measurements are based on detailed experimental characterization of the electronic structure in photoemission and inverse photoemission. More 
importantly, the identification of a surface electronic structure distinct from the bulk can be exploited to provide indications of surface piezoelectric effects that may differ from the bulk.

The value in characterizing the electronic band structure is not simply to assist in providing more signatures of pyroelectricity and piezoelectricity, but also help in assessing carrier mobilities. Lithium tetraborate remains one of the few piezoelectric materials for which there is a complete experimental band structure mapping [7]. This latter body of experimental data indicates that theory, in particular density functional theory, is not a completely infallible guide to the details of band structure of piezo-electric materials.

\section{The Electronic Structure of Lithium Tetraborate}

The pyroelectric lithium tetraborate is of space group of $I 4_{1} \mathrm{~cd}$, and a rather complex tetragonal crystal with 104 atoms per unit cell, with dimensions $\mathrm{a}=9.479 \AA$ and $\mathrm{c}=10.290 \AA$ [8-13]. While several band structure calculations exist [14-15], there is no uniform consistency in the predicted band structure. Recent density functional theory (DFT) band structure calculations [14] suggest that the hole mass is larger than the electron mass. In other words, the dispersion of the valence bands should be small compared to the expected dispersion of the conduction bands. Only recently $[5,7]$ has there has been experimental confirmation of any of the key predictions of the calculated band structure, beyond the band gap [5,7,16-18] and some of the optical properties [15].

Both $\mathrm{Li}_{2} \mathrm{~B}_{4} \mathrm{O}_{7}(100)$ and $\mathrm{Li}_{2} \mathrm{~B}_{4} \mathrm{O}_{7}(110)$ exhibit, in combined photoemission and inverse photoemission studies, a density of states that qualitatively agrees with the results from model bulk band structure calculations for $\mathrm{Li}_{2} \mathrm{~B}_{4} \mathrm{O}_{7}$ [10-11], as seen in Figure 1. For $\mathrm{Li}_{2} \mathrm{~B}_{4} \mathrm{O}_{7}(100)$ the band gaps obtained from combined photoemission and inverse photoemission are $10.1 \pm 0.5 \mathrm{eV}$ and $8.9 \pm 0.5 \mathrm{eV}$ with the in plane component of $\underline{\mathbf{E}}$ aligned along the [011] and [010] orientations, respectively. For $\mathrm{Li}_{2} \mathrm{~B}_{4} \mathrm{O}_{7}(110)$, the band gaps are $9.8 \pm 0.5 \mathrm{eV}$ in both the [001] and [110] orientations. In general, the combined photoemission and inverse photoemission measure the direct band gap, but as final state spectroscopies. Consequently, perfect agreement with a ground state calculation, such as density functional theory, is usually not possible and unlikely beyond the qualitative; although the agreement as seen here between experiment and the prior band structure calculations [14] is generally quite good.

The Fermi level is placed slightly closer to the conduction band edge in the combined experimental photoemission and inverse photoemission spectra, as seen in Figure 1. This indicates that both the $\mathrm{Li}_{2} \mathrm{~B}_{4} \mathrm{O}_{7}(100)$ and $\mathrm{Li}_{2} \mathrm{~B}_{4} \mathrm{O}_{7}(110)$ surfaces are n-type, although (100) is more n-type than (110). While we have not measured the majority carrier, the Fermi level placement is consistent with the known bulk properties where the majority of defects seen in these $\mathrm{Li}_{2} \mathrm{~B}_{4} \mathrm{O}_{7}(100)$ and $\mathrm{Li}_{2} \mathrm{~B}_{4} \mathrm{O}_{7}(110)$ were oxygen vacancies [12,19]. Point defects comprising of isolated oxygen vacancies, and to a smaller extent isolated lithium vacancies, with a very small trace of $\mathrm{Cu}$ impurities were evident in electron paramagnetic resonance (EPR) and electron-nuclear double resonance (ENDOR), in agreement with prior measurements [12]. The existence of these oxygen vacancies is also consistent with a placement of the Fermi level closer to the conduction band edge as a result of oxygen vacancies. 
Figure 1. A comparison of the combined experimental photoemission (left) and inverse photoemission (right) data, in $\mathrm{E}_{-} \mathrm{E}_{\mathrm{F}}$, with theoretical expectations. The theoretical density of the bulk band states of crystalline $\mathrm{Li}_{2} \mathrm{~B}_{4} \mathrm{O}_{7}$; (a) obtained by the LDA PW1PW is adapted from Islam et al. [14]. The combined experimental photoemission (left) and inverse photoemission (right) data for $\mathrm{Li}_{2} \mathrm{~B}_{4} \mathrm{O}_{7}(100)$, with the in-plane component of the incident light $\underline{\mathbf{E}}$ for photoemission oriented along [011]; (b) and [010]; (c) are shown along with the data for $\mathrm{Li}_{2} \mathrm{~B}_{4} \mathrm{O}_{7}(110)$ with the in-plane component of the incident light $\underline{\mathbf{E}}$ for photoemission oriented along [001]; (d) and [110]; (e) For the photoemission, the photon energy is $56 \mathrm{eV}$ and the synchrotron light is incident at 45 degrees with respect to sample normal. The electrons were either collected along the surface normal (photoemission) or incident along the surface normal (inverse photoemission). The sample temperature for these measurements was $623 \pm 5 \mathrm{~K}$, to reduce surface charging. Adapted from [7].

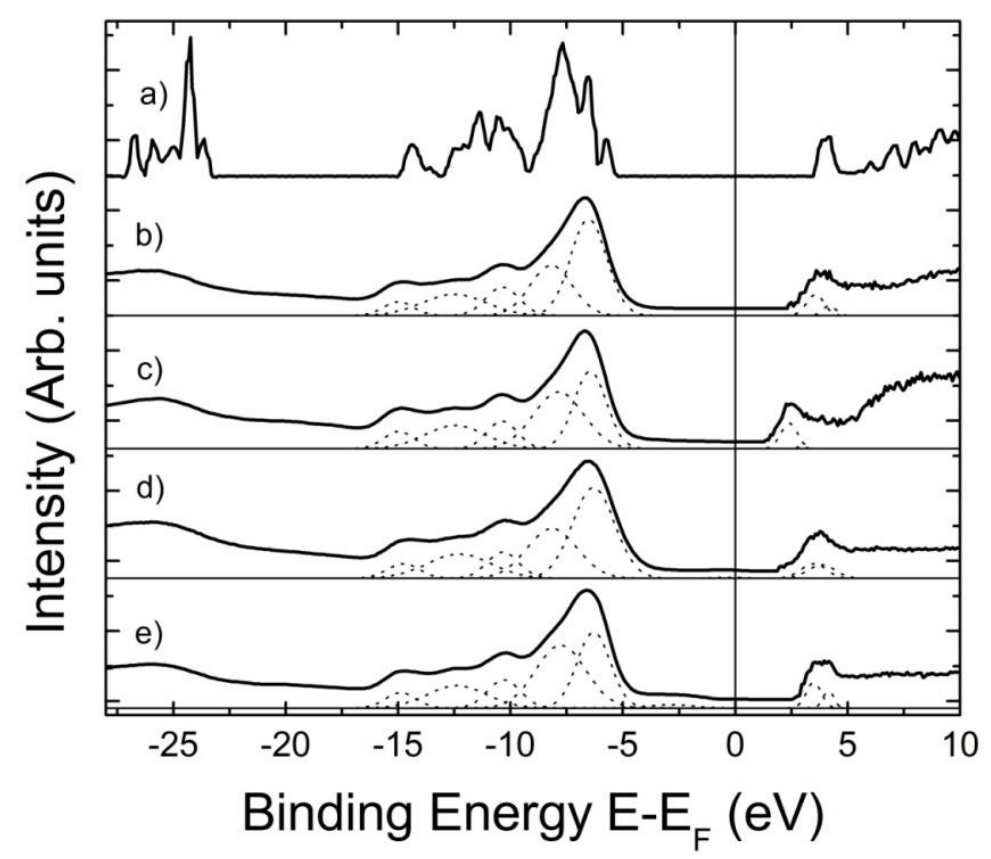

The general prediction that the hole mass should be far greater than the electron mass, based on the calculated band structure [14], is supported by the experimental band mappings of the $\mathrm{Li}_{2} \mathrm{~B}_{4} \mathrm{O}_{7}(100)$ and $\mathrm{Li}_{2} \mathrm{~B}_{4} \mathrm{O}_{7}(110)$ surfaces [7]. So far there has been no evidence of dispersion of the occupied bands; that is to say there is no strong indication of wave vector dependent changes in binding energy, with either photon energy or emission angle, for the filled states [7]. The absence of any such dispersion suggests that the occupied states for both the $\mathrm{Li}_{2} \mathrm{~B}_{4} \mathrm{O}_{7}(110)$ and $\mathrm{Li}_{2} \mathrm{~B}_{4} \mathrm{O}_{7}(100)$ surfaces are characterized by a very heavy mass. From the absence of dispersion in the photoemission data [7], we can assign a lower bound to the hole effective mass of 10 [m*/me . This lower bound is limited by the feature widths in photoemission, and the limited wave vector and energy resolution, and of course the effective mass could be much greater.

The absence of dispersion with photon energy, in angle-resolved photoemission, is often attributed to the conservation of two dimensionality of state, that is to say a surface state. We do not believe that this possible attribution of the states seen in photoemission to surface states is a 
reasonable assignment in the case for the $\mathrm{Li}_{2} \mathrm{~B}_{4} \mathrm{O}_{7}(100)$ and $\mathrm{Li}_{2} \mathrm{~B}_{4} \mathrm{O}_{7}(110)$ surfaces. These occupied states, aside from the surface state identified below, do not fall into a gap of the projected band structure and indeed are heavy mass states that simply do not disperse very much. Nor can the problem with the dispersion (the absence of observed dispersion) be related to disorder at the surface: the inverse photoemission exhibits band dispersion of the empty states consistent with the surface Brillouin zone [7].

Figure 2. The incidence angle dependent inverse photoemission spectra for the $\mathrm{Li}_{2} \mathrm{~B}_{4} \mathrm{O}_{7}(110)$ with increasing incidence angle (wave vector) along the [110] direction. The image state wave vector dependent (incidence angle) dispersion (see text) is indicated by the arrows. The unoccupied state binding energies are given in terms of E-E $E_{F}$. Adapted from [7,17].

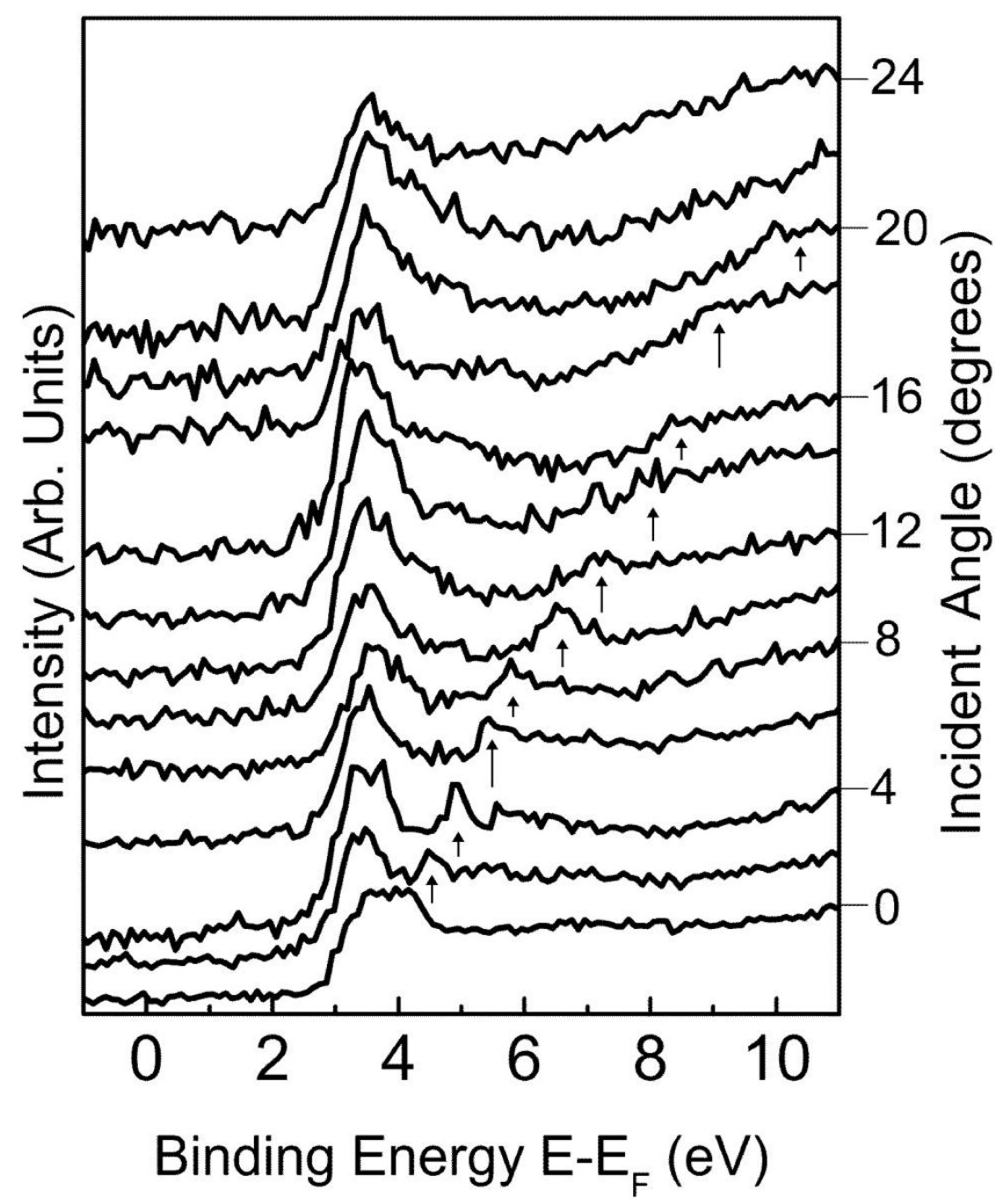

In contrast to the results garnered from the angle-resolved photoemission, dispersion is evident in empty states observed in the angle-resolved inverse photoemission results [7], obtained as a function of electron incidence angle $(\theta)$, as seen in Figure 2. The parallel momentum $\left(k_{\|}\right)$in inverse photoemission can be derived as follows from the electron kinetic energy and the incidence angle $(\theta)$ with respect to the surface normal [20-21]: 


$$
k_{\|}=\sqrt{\frac{2 m}{\mathrm{~h}^{2}} E_{K i n}} \sin (\theta)=0.51198 \sqrt{E_{K i n}\{e V\}} \sin (\theta)\left\{A^{-1}\right\}
$$

Despite the much lower resolution of inverse photoemission, one is able to observe dispersion of the bands at the conduction band minimum, as shown in Figure 2 and plotted in Figure 3. The periodicity in the dispersion is consistent with the expected Brillouin zone of the $\mathrm{Li}_{2} \mathrm{~B}_{4} \mathrm{O}_{7}(110)$ surface, for the states near the conduction band minimum, as plotted in Figure 3, along both the [001] and [110] directions. Again, this could be related to the surface electronic structure, particularly as inverse photoemission is notoriously surface sensitive, but these states also do not fall into a gap of the projected band structure.

Figure 3. The unoccupied state binding energies versus the surface parallel wave vector are mapped for the $\mathrm{Li}_{2} \mathrm{~B}_{4} \mathrm{O}_{7}(110)$ along the [110] direction. ( $\left.\bullet\right)$ denotes the lowest unoccupied molecular orbital, $(\bullet)$ a higher energy empty state, and $(\boldsymbol{\Delta})$ an image state. The surface Brillouin zone critical points are denoted at top. Adapted from [7].

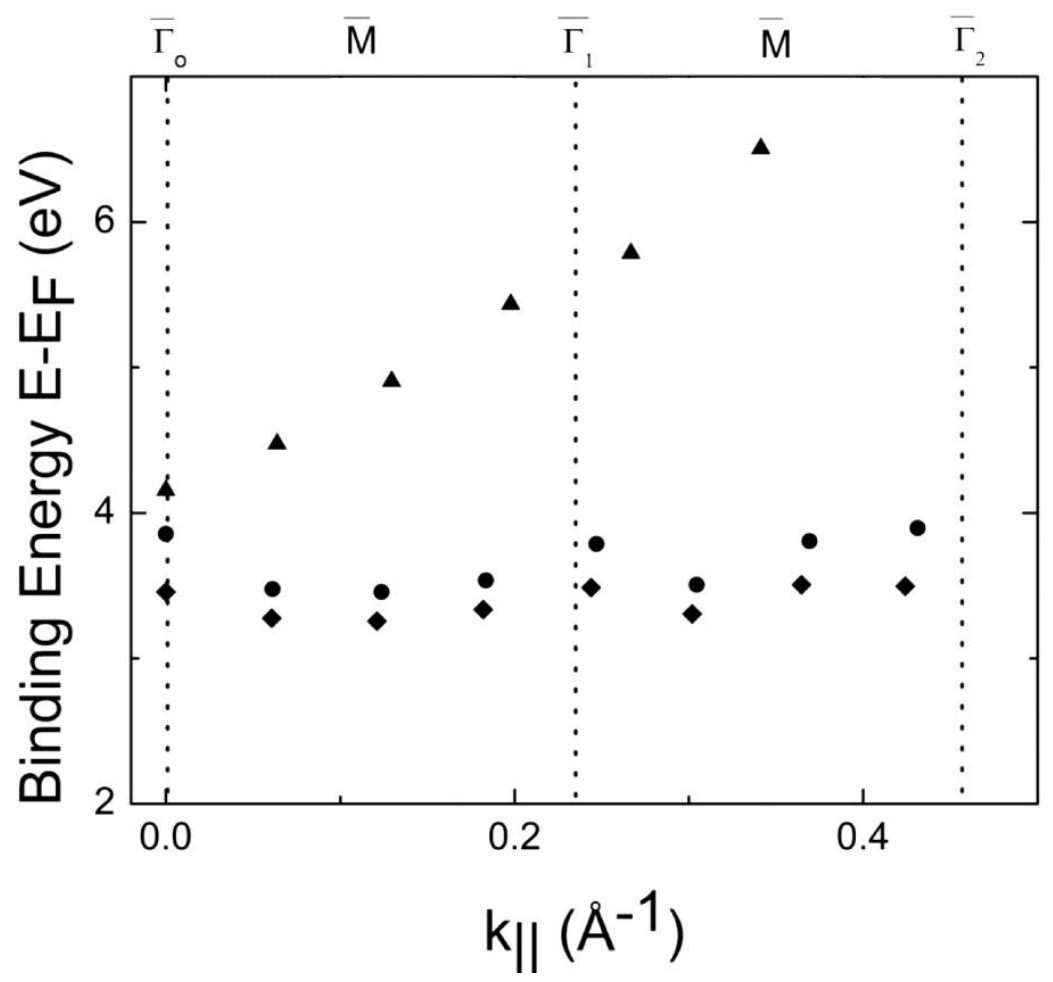

The trend of the dispersion of the states at the conduction band minimum, towards the Fermi level with increasing wave vector away from the center of the surface Brillouin zone, is qualitatively the opposite trend of one of the DFT calculation [14]. The semi-empirical LDA calculations of Adamiv and coworkers [15] provided a much smaller band gap than observed in the combined photoemission and inverse photoemission (Figure 1). The trend of the dispersion in the semi-empirical LDA calculations of Adamiv and coworkers [15] (Figure 4), however, towards the Fermi level with increasing wave vector away from the center of the surface Brillouin zone is the same qualitative behavior seen with the unoccupied states near the conduction band minimum in the band mapping obtained from inverse photoemission [7], as illustrated in Figure 3. 
The qualitative agreement in the unoccupied band dispersion relationship was obtained between experiment and a band structure of $\mathrm{Li}_{2} \mathrm{~B}_{4} \mathrm{O}_{7}$ calculated on the basis of crystallographic analysis of phonon parameters, and structural fragments of $\mathrm{BO}_{3}, \mathrm{BO}_{4}, \mathrm{LiO}_{4}$ and $\mathrm{LiO}_{6}$. [15-16]. The 2s-, $2 \mathrm{p}_{\mathrm{x}^{-}}$, $2 \mathrm{p}_{\mathrm{y}^{-}}, 2 \mathrm{p}_{\mathrm{z}^{-}} \mathrm{B}$ and $2 \mathrm{~s}-\mathrm{Li}$ orbitals served as a basis set for the secular equations. The $2 \mathrm{~s}-\mathrm{O}$ orbitals were introduced within a first order perturbation approach [15]. Screening effects were taken into account to obtain better agreement between calculated energy gaps and experimental data. An additional correction (caused by deeper energy bands) was introduced using optical functions obtained from the fundamental reflection spectra [15]. The energy band structure (including a third coordination sphere) was calculated with a final correction according to the optical functions, to better achieve a full quantitative agreement. This energy band structure is shown in Figure 4.

Figure 4. The Calculated electronic bulk band structure of lithium tetraborate $\mathrm{Li}_{2} \mathrm{~B}_{4} \mathrm{O}_{7}$. Adapted from [15].

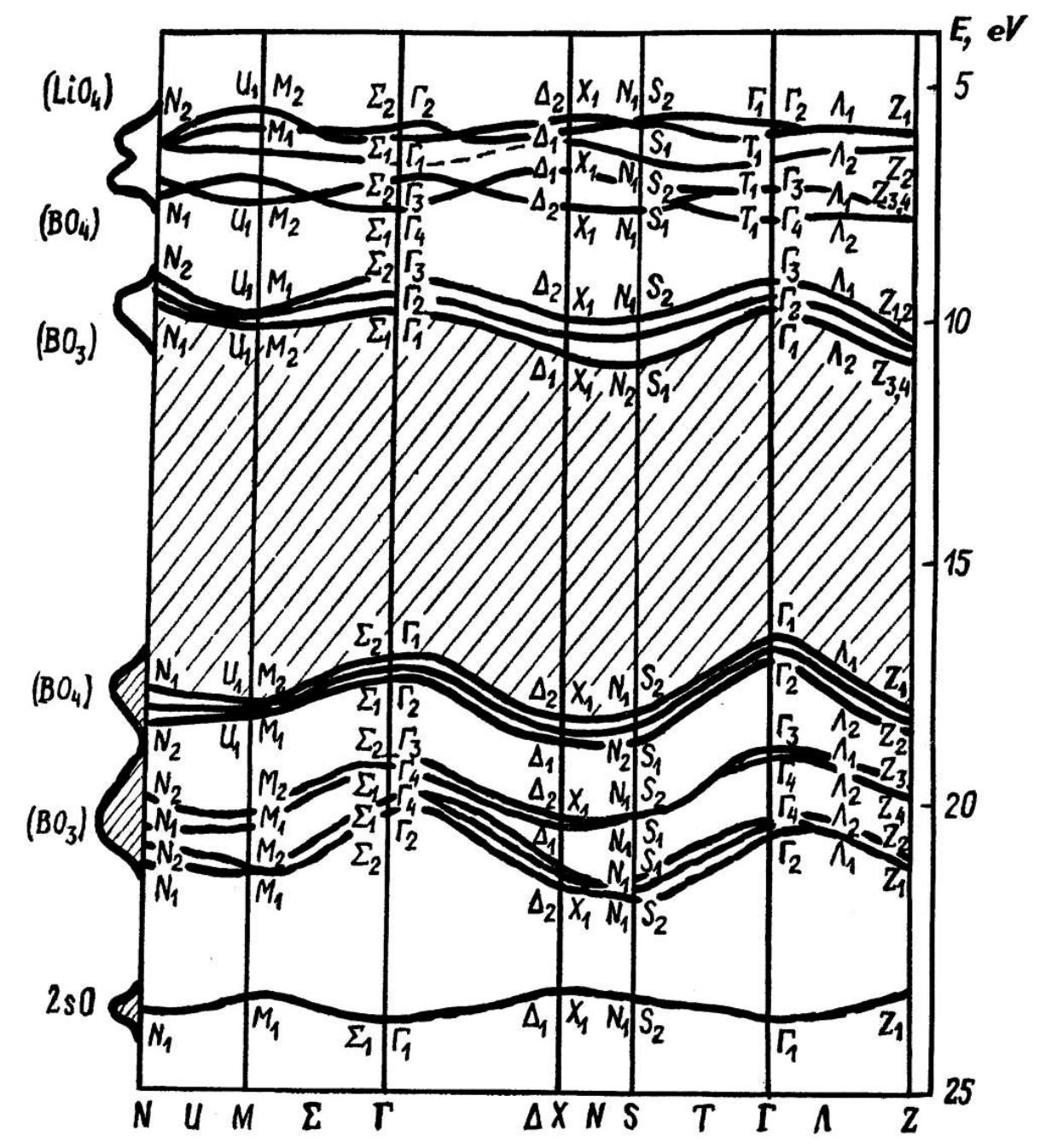

In this latter calculation of the band structure [15], a maximal correction (up to $1.5 \mathrm{eV}$ ) was necessary for electron bands originating from the $\mathrm{LiO}_{6}$ octahedral. There is a significant dispersion of the band structure is observed for the valence zone top along $\Gamma-\mathrm{X}-\mathrm{S}$ direction that is determined by the $\mathrm{BO}_{4}$ clusters but this is not observed in the experimental band mapping. A valence band originating from $\mathrm{BO}_{3}$-orbitals is situated below the latter. The $2 \mathrm{~s}-\mathrm{O}$ states are responsible for a 
nearly dispersionless band lying $3 \mathrm{eV}$ below the bands of $\mathrm{BO}_{3}$ in origin. The states at the conduction band minimum are built of the antibonding $\mathrm{BO}_{3}$-orbitals. Antibonding $\mathrm{BO}_{4}$-orbitals and $\mathrm{LiO}_{4}$-orbitals are involved in formation of the next grouping of bands (with energies higher than previous ones by about $4 \mathrm{eV}$ ). The $\mathrm{LiO}_{6}$ clusters produce a high energy band which is not generally considered to be involved in the optical transitions.

The $\mathrm{BO}_{3}$ and $\mathrm{BO}_{4}$ structural fragments in the $\mathrm{Li}_{2} \mathrm{~B}_{4} \mathrm{O}_{7}$ single crystals exhibit mainly covalent bonding, while the $\mathrm{LiO}_{4}$ and $\mathrm{LiO}_{6}$ fragments are basically ionic. The covalent bond is determined by the $2 \mathrm{p}-\mathrm{B}$ and $2 \mathrm{p}-\mathrm{O}$ strongly hybridized orbitals with a small asymmetry towards boron and oxygen atoms. The $2 \mathrm{p}-\mathrm{O}$ orbitals serve as bonding orbitals between different clusters of the $\mathrm{Li}_{2} \mathrm{~B}_{4} \mathrm{O}_{7}$ system as well. The hybridization is substantially diminished in the middle of the $\mathrm{LiO}_{4}$ and $\mathrm{LiO}_{6}$ structural components and, therefore, the polarizability of the chemical bonds increases because of a separation of electron charge between the $2 \mathrm{~s}-\mathrm{Li}$ and $2 \mathrm{p}-\mathrm{O}$ orbitals. Generally the electron densities calculated in this manner are in very good agreement with the combined photoemission and inverse photoemission, as noted above.

From inverse photoemission, the electron effective masses for the unoccupied $\mathrm{Li}_{2} \mathrm{~B}_{4} \mathrm{O}_{7}(110)$ and $\mathrm{Li}_{2} \mathrm{~B}_{4} \mathrm{O}_{7}(100)$ states near the conduction band minimum has been estimated [7] to be in the region of $-0.15 \pm 0.1\left[\mathrm{~m} * / \mathrm{m}_{\mathrm{e}}\right]$.

A nearly parabolic lighter mass band is also seen to disperse independent of the surface Brillouin zone, as shown in Figures 2 and 3, again along both the [001] and [110] directions of the surface Brillouin zone for the $\mathrm{Li}_{2} \mathrm{~B}_{4} \mathrm{O}_{7}(110)$ surface. This lighter mass band observed at binding energies $\left(E-E_{F}\right)$ well above the Fermi level for the $\mathrm{Li}_{2} \mathrm{~B}_{4} \mathrm{O}_{7}(110)$ surface is an image state, as discussed later. In fact, there was no image potential state observed for the $\mathrm{Li}_{2} \mathrm{~B}_{4} \mathrm{O}_{7}(100)$ surface.

\subsection{Surface states within the gap of the projected bulk band structure}

While the valence band maximum and band gap is in reasonable agreement with expectations, from angle resolved photoemission, there is evidence for states within the valence band maximum to conduction band minimum gap (the insulator band gap), as seen in Figure 5. In general, there is little light polarization dependence observed in the photoemission spectra taken for both the $\mathrm{Li}_{2} \mathrm{~B}_{4} \mathrm{O}_{7}(100)$ and $\mathrm{Li}_{2} \mathrm{~B}_{4} \mathrm{O}_{7}$ (110) surfaces [7]. As seen in Figure 5, the light polarization dependent photoemission in the valence band region of the $\mathrm{Li}_{2} \mathrm{~B}_{4} \mathrm{O}_{7}(110)$ surface exhibits few differences between a light incidence angle of $70^{\circ}$, placing the electric vector $\underline{\mathbf{E}}$ more along the surface normal and a light incidence angle of $45^{\circ}$. Yet with a light incidence angle of $70^{\circ}$, there is a small density of states within the gap placed close to the Fermi level, as seen in Figure 5. In this region of energy near the Fermi level, within the bulk band gap and below $\mathrm{E}_{\mathrm{F}}$, the presence of surface states has been marked by an " $\mathrm{S}$ " in Figure 5.

As these $\mathrm{Li}_{2} \mathrm{~B}_{4} \mathrm{O}_{7}(110)$ surface states fall into the gap of the projected bulk band structure (Figure 1a) [14], we can initially conclude that these observed occupied states are, in fact, true surface states [7]. The observed intensities of these surface states in photoemission are clearly affected by light polarization (Figure 5) and these surface states are likely of $s$ or $p_{z}$ character (with $\mathrm{z}$ along the surface normal), given that they are enhanced with incident light where the electric vector $\underline{\mathbf{E}}$ is more along the surface normal. Certainly for the $\mathrm{Li}_{2} \mathrm{~B}_{4} \mathrm{O}_{7}(110)$ surface, the possibility 
of surface states must be given serious consideration as a Li 1s surface to bulk core level shift has been observed for this surface [17].

Figure 5. Experimental light polarization dependent photoemission spectra for $\mathrm{Li}_{2} \mathrm{~B}_{4} \mathrm{O}_{7}(110)$ oriented along [001] with regards to the in-plane component of $\underline{\mathbf{E}}$. The photon energy is $95 \mathrm{eV}$ with the photoelectrons collected along the surface normal; the light incidence angle was (a) 70 degrees $\{\Delta \Delta \Delta\}$ or (b) 45 degrees $\{-\}$ with respect to surface normal. The arrow indicates the position of the surface contribution (S) to the occupied density of states above the bulk density of states valence band maximum. The sample temperature for these measurements was $623 \pm 5 \mathrm{~K}$, to reduce surface charging. Adapted from [7,17].

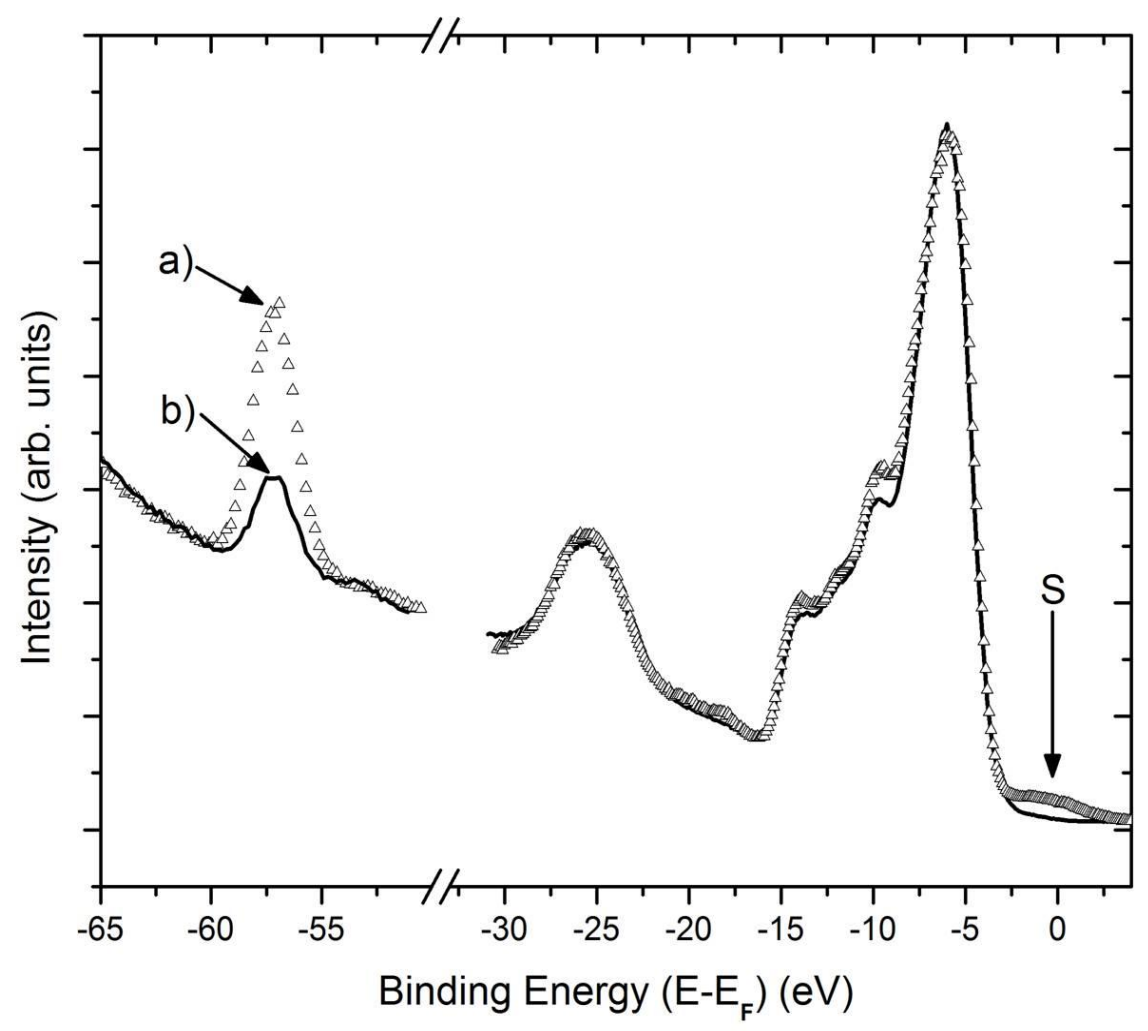

\subsection{The Li 1s surface-to-bulk core level shift}

Through the use of angle-resolved photoemission spectra taken from $\mathrm{Li}_{2} \mathrm{~B}_{4} \mathrm{O}_{7}(110)$ with the in-plane component of $\underline{\mathbf{E}}$ oriented along [001] and at a photon energy of $95 \mathrm{eV}$, we have identified the Li 1 s core level photoemission feature, as shown in Figures 5 and 6. After corrections for photovoltaic charging (as discussed later (vide infra) and elsewhere [5,7,16-18]), we place the $\mathrm{Li}$ 1s shallow core level binding energies at $-56.7 \pm 0.4$ to $-56.5 \pm 0.4 \mathrm{eV}$ depending on the surface termination (crystal orientation). These values are largely dominated by the bulk Li 1s core level binding energy contributions because of the normal photoelectron emission geometry. By increasing the electron emission angle, two components can be easily resolved for the $\mathrm{Li}_{2} \mathrm{~B}_{4} \mathrm{O}_{7}(110)$ surface at $-56.5 \pm 0.4 \mathrm{eV}$ and $-53.7 \pm 0.5 \mathrm{eV}$, as illustrated in Figure 6 . 
Figure 6. Angle-resolved photoemission spectra of $\mathrm{Li}_{2} \mathrm{~B}_{4} \mathrm{O}_{7}(110)$ in the region of the $\mathrm{Li} 1 \mathrm{~s}$ core level, for photoelectron emission angles of $20^{\circ}$ and $0^{\circ}$. In both cases, the in-plane component of $\underline{\mathbf{E}}$ was oriented along [001] with a light incidence angle $45^{\circ}$ and with photon energy of $95 \mathrm{eV}$. The figure shows spectra with the instrumental background and secondary electron tail subtracted from the spectra with fittings to the Li 1s bulk and surface peaks, denoted B (bulk component contribution) and S (surface component contribution), respectively. The sample temperature for these measurements was $623 \pm 5 \mathrm{~K}$, to reduce surface charging. Adapted from [17].

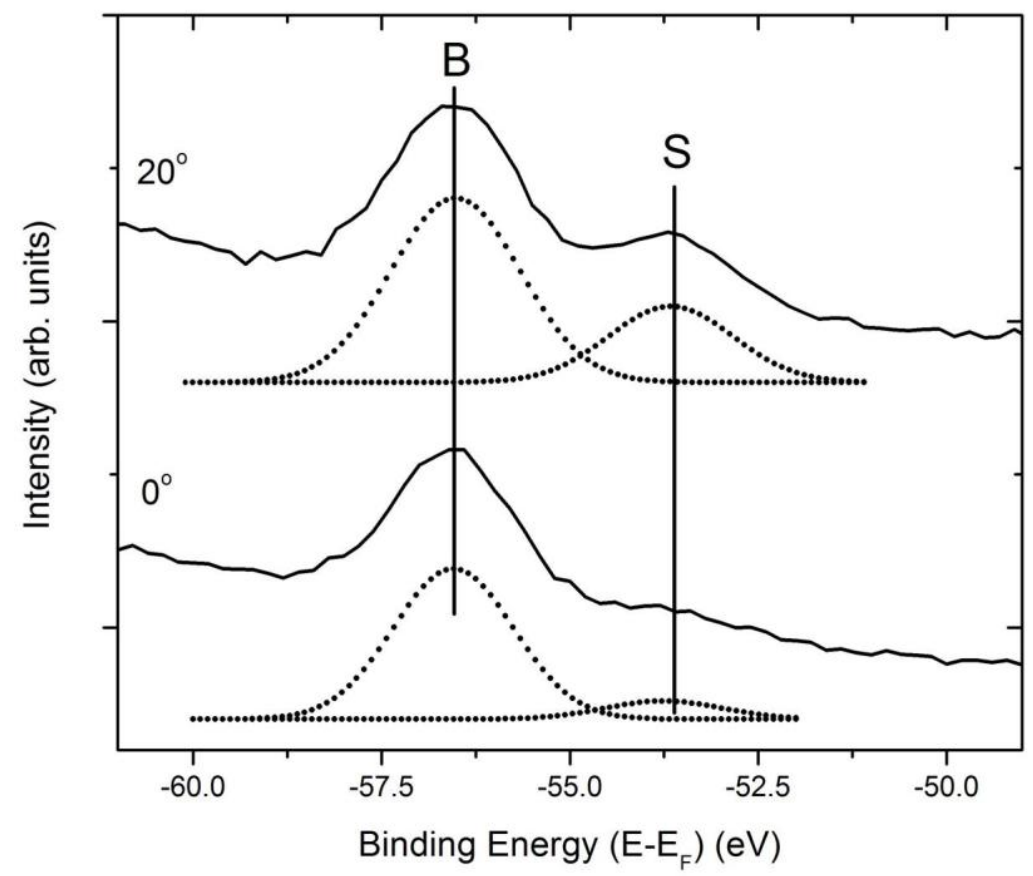

From prior studies of the surface-to-bulk core level shift [22-23], the reasonable expectation is to observe an increase in the intensity of the surface component of the core level with increasing emission angle. The intensity of the $\mathrm{Li} 1$ s core level component for the $\mathrm{Li}_{2} \mathrm{~B}_{4} \mathrm{O}_{7}(110)$ surface at the smaller binding energy of $-53.7 \pm 0.5 \mathrm{eV}$ is shown to increase with increasing emission angle and thus we assign the Li 1s component at this binding energy as the surface component. The feature at a higher binding energy of $-56.5 \pm 0.4 \mathrm{eV}$ is attributed to the $\mathrm{Li} 1 \mathrm{~s}$ bulk component for $\mathrm{Li}_{2} \mathrm{~B}_{4} \mathrm{O}_{7}(110)$.

The temperature dependence of this surface-to-bulk core level shift we later exploit to study possible surface piezo-electric effects (vide infra).

\subsection{The image state at the $\mathrm{Li}_{2} \mathrm{~B}_{4} \mathrm{O}_{7}(110)$ surface}

Image states are characteristic of clean, flat, largely defect free surfaces. The absence of any image states for the $\mathrm{Li}_{2} \mathrm{~B}_{4} \mathrm{O}_{7}(100)$ surface is consistent with the presence of defects at this surface; defects which are very likely surface oxygen vacancies, as has been noted above. The presence of an image state for the $\mathrm{Li}_{2} \mathrm{~B}_{4} \mathrm{O}_{7}(110)$ surface (Figure 2 and Figure 3), indicates that this surface is largely defect free with a very flat surface potential. We note that the $\mathrm{Li}_{2} \mathrm{~B}_{4} \mathrm{O}_{7}(110)$ surface image state dispersion is not periodic in nature and, in fact, is seen to be simply parabolic along both the 
[001] and [110] directions of the surface Brillouin zone. For this to occur, the surface potential of the $\mathrm{Li}_{2} \mathrm{~B}_{4} \mathrm{O}_{7}(110)$ surface must be so flat that the image state is not perturbed by the surface crystallography, and disperses almost independently of the surface Brillouin zone (Figure 3).

While, as we noted above, the $\mathrm{Li}_{2} \mathrm{~B}_{4} \mathrm{O}_{7}(110)$ surface is distinguished by a surface state within a gap of the projected bulk band structure (Figure 5), this surface also exhibits very little light polarization dependence of the bulk valence band states [7,17]. It is this same surface with a small but significant off-axis pyroelectric effect [5], as discussed below. Both effects may combine to reduce the surface potential variations leading to a parabolic image potential state. What is also evident is that the image state for the $\mathrm{Li}_{2} \mathrm{~B}_{4} \mathrm{O}_{7}(110)$ surface possesses a very light effective mass of $\mathrm{m}^{*} / \mathrm{m}_{\mathrm{e}}=0.06 \pm 0.02$. Such a light mass image state is much less likely to be perturbed by the surface potential, as is observed [7].

\section{Piezoelectricity and Off-Axis Pyroelectricity in Lithium Tetraborate}

It has been known for some time that single crystals of $\mathrm{Li}_{2} \mathrm{~B}_{4} \mathrm{O}_{7}$ exhibit piezoelectric properties $[24,25]$ as well as pyroelectric properties $[25,26]$. The piezoelectric properties may make lithium tetraborate attractive for surface acoustic wave (SAW) device applications [24,27-31]. Defining

$$
\begin{gathered}
\mathrm{P}_{1}=\mathrm{d}_{\mathrm{lij}} \sigma_{\mathrm{ij}} \\
\underline{\mathrm{E}}_{\mathrm{l}}=-\mathrm{g}_{\mathrm{ljk}} \sigma_{\mathrm{jk}} \\
\mathrm{P}_{1}=-\mathrm{e}_{\mathrm{ljk}} \varepsilon_{\mathrm{jk}} \\
\underline{\mathrm{E}}_{1}=-\mathrm{h}_{\mathrm{lij}} \varepsilon_{\mathrm{ij}}
\end{gathered}
$$

where again $\mathrm{P}_{1}$ is the electric polarization vector, $\sigma_{\mathrm{ij}}$ is the mechanical stress, $\varepsilon_{\mathrm{jk}}$ is the elastic deformation, $\mathrm{d}_{\mathrm{lij}}$ are the piezoelectric coefficients $\left(10^{-12} \mathrm{C} / \mathrm{N}\right), \mathrm{e}_{\mathrm{ljk}}$ are the piezoelectric stress constants $\left(\mathrm{C} / \mathrm{m}^{2}\right), \mathrm{g}_{\mathrm{ljk}}$ are the piezoelectric constants $\left(\mathrm{m}^{2} / \mathrm{C}\right)$, while $\mathrm{h}_{\mathrm{lij}}$ are the piezoelectric deformation constants $\left(10^{9} \mathrm{~N} / \mathrm{C}\right)$. The piezoelectric coefficients have now been pretty well established and there is convergent agreement, as summarized in Table 1.

Table 1 indicates that the piezoelectric constants of $\mathrm{Li}_{2} \mathrm{~B}_{4} \mathrm{O}_{7}$ are placed between piezoelectric constants of $\mathrm{LiNbO}_{3}\left(\mathrm{~d}_{15}=74 \times 10^{-12} \mathrm{C} / \mathrm{N}\right.$ and $\left.\mathrm{d}_{33}=18.9 \times 10^{-12} \mathrm{C} / \mathrm{N}\right)$ and piezo-quartz $\left(\mathrm{d}_{11}=2.3 \times 10^{-12} \mathrm{C} / \mathrm{N}\right)$. The piezoelectric measurements [25,34] show high values for the hydrostatic piezoelectric constants $\mathrm{g}_{33}=(0.200-0.223) \mathrm{Vm} / \mathrm{N}$ and $\mathrm{g}_{\mathrm{h}}=(0.100-0.179) \mathrm{Vm} / \mathrm{N}$ providing some indication of the interest in $\mathrm{Li}_{2} \mathrm{~B}_{4} \mathrm{O}_{7}$ as a possible pressure sensor. The piezoelectric constant $\mathrm{g}_{33}$ of $\mathrm{Li}_{2} \mathrm{~B}_{4} \mathrm{O}_{7}$ is among the largest known [25]. The piezoelectric constants $d_{31}$ and $d_{32}$, in the temperature range from $4 \mathrm{~K}$ to $900 \mathrm{~K}$, decrease monotonically with decreasing temperature [36].

Although perhaps better known as a piezoelectric, lithium tetraborate, as indicated at the outset, does have an appreciable pyroelectric coefficient along the [001] direction, in the region of $100 \mathrm{~K}$ to $250 \mathrm{~K}$ [25-26], as plotted in Figure 7c. The [110] and [100] crystal directions are orthogonal to the polar [001] direction for the tetragonal crystal lattice and thus candidates for the study of an 
off-axis pyroelectric effect, which makes lithium tetraborate a nice playground for the demonstration of a secondary pyroelectric effect.

Table 1. A summary of the experimentally determined piezoelectric characteristics of $\mathrm{Li}_{2} \mathrm{~B}_{4} \mathrm{O}_{7}$ single crystals.

\begin{tabular}{|c|c|c|c|c|c|c|c|c|}
\hline $\begin{array}{l}\text { Constan } \\
\text { ts }\end{array}$ & Units & [32] & [31] & [33] & [28] & [34] & [25] & [35] \\
\hline $\mathrm{d}_{15}$ & \multirow{3}{*}{$\left(10^{-12} \mathrm{C} / \mathrm{N}\right)$} & & & 3.2 & & 6.33 & - & 8.07 \\
\hline $\mathrm{d}_{33}$ & & & & 19.8 & & 20.4 & 24.0 & 19.4 \\
\hline $\mathrm{d}_{31}$ & & & & -3.2 & & -2.02 & -4.8 & -2.58 \\
\hline $\mathrm{e}_{15}$ & \multirow{3}{*}{$\left(\mathrm{C} / \mathrm{m}^{2}\right)$} & 0.39 & 0.36 & 0.36 & 0.472 & 0.35 & & \\
\hline$e_{31}$ & & 0.24 & 0.19 & 0.19 & 0.290 & 0.38 & & \\
\hline$e_{33}$ & & 0.93 & 0.89 & 0.87 & 0.928 & 0.88 & & \\
\hline $\mathrm{g}_{15}$ & \multirow{3}{*}{$\left(\mathrm{m}^{2} / \mathrm{C}\right)$} & 0.082 & & & & & & \\
\hline $\mathrm{g}_{31}$ & & -0.032 & & & & & & \\
\hline $\mathrm{g}_{33}$ & & 0.231 & & & & & & \\
\hline $\mathrm{h}_{15}$ & \multirow{3}{*}{$\left(10^{9} \mathrm{~N} / \mathrm{C}\right)$} & 4.95 & & & & & & \\
\hline $\mathrm{h}_{31}$ & & 3.34 & & & & & & \\
\hline$h_{33}$ & & 12.9 & & & & & & \\
\hline
\end{tabular}

\subsection{The off-axis pyroelectric effect observed for lithium tetraborate}

There is a pyroelectric current along the [110] direction of stoichiometric $\mathrm{Li}_{2} \mathrm{~B}_{4} \mathrm{O}_{7}$ so that the pyroelectric coefficient is nonzero [5]. From the current and rate of change in temperature, the approximate pyroelectric coefficient along the [110] direction (Equation 3) has been determined [5]. Along the polar [001] direction, the pyroelectric coefficient $p_{\mathrm{i}}$ is about $125 \mu \mathrm{C} / \mathrm{m}^{2} \cdot \mathrm{K}$ at $120 \mathrm{~K}$ [25]. Along the orthogonal [110] direction, the pyroelectric coefficient $p_{\mathrm{i}}$ reaches a maximal value of about 0.2 to $0.4 \mu \mathrm{C} / \mathrm{m}^{2} \cdot \mathrm{K}$ [5], as illustrated in Figure 7, and is clearly much smaller than along the $\langle 001\rangle$ direction of spontaneous polarization. Indeed, the pyroelectric coefficient along the $<110>$ direction is some 300 to 1000 times smaller than the conventional pyroelectric coefficient measured along the polar $<001>$ lithium borate crystallographic direction in the temperature region of $70 \mathrm{~K}$ to $250 \mathrm{~K}$. The pyroelectric coefficient $p_{\mathrm{i}}$ values along the [110] direction remain qualitatively similar in their temperature dependence as obtained from the currents measured from a range of heating and cooling rates.

As in some prior measurements [26], strong variations with temperature in the pyroelectric current and associated pyroelectric coefficient along the [110] direction have been measured [5], as shown in Figure 7. Indeed, the pyroelectric coefficient does not show the same temperature dependence along the [110] direction as has been described [25-26] along the [001] direction, as indicated in Figure 7. The fact that the measured pyroelectric currents and resulting pyroelectric coefficients along the [110] direction differ qualitatively from those measured along the [001] polar direction [25] is compelling evidence that the measured pyroelectric coefficient along the [110] direction is not the result of a crystal miscut and therefore cannot be a projection of the expected [001] pyroelectric current off the polar axis [5]. 
Figure 7. (a) Pyroelectric current in the cooling cycle for the $\mathrm{Li}_{2} \mathrm{~B}_{4} \mathrm{O}_{7}$ single crystal in the $\langle 110\rangle$ direction, at a cooling rate of roughly 0.25 degrees/sec, adapted from [5]; (b) temperature dependence of the pyroelectric coefficient in the cooling cycle for the $\mathrm{Li}_{2} \mathrm{~B}_{4} \mathrm{O}_{7}$ single crystal in the [110] direction, also adapted from [5]; (c) temperature dependence of the elastic stiffness constant $\mathrm{C}_{33}^{\mathrm{D}}$ for the $\mathrm{Li}_{2} \mathrm{~B}_{4} \mathrm{O}_{7}$ single crystal along the polar $c$-axis (solid line), adapted from [37] and the polar [001] pyroelectric coefficient (dashed line), adopted from [25].

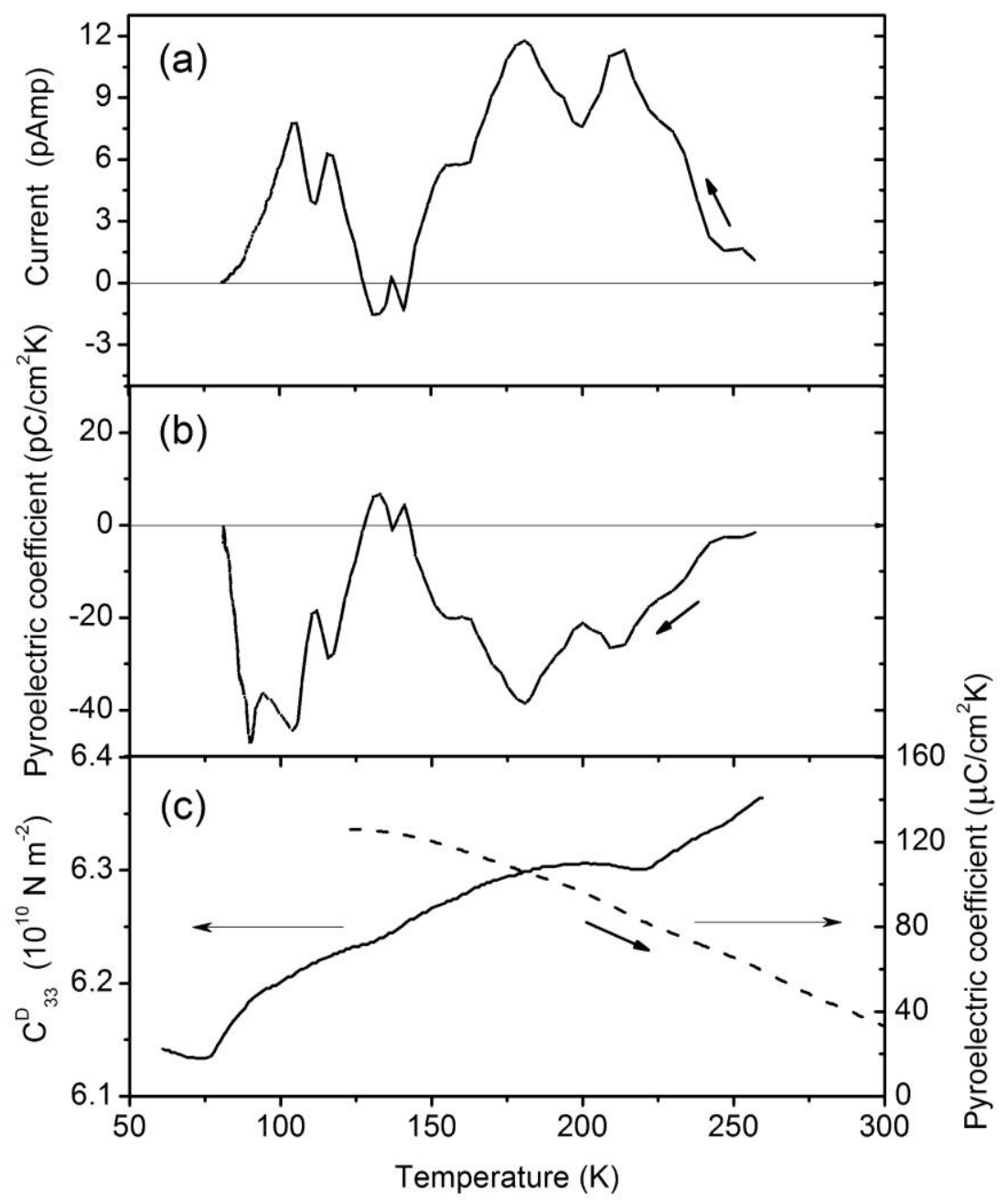

The pyroelectric current provides dramatic relative changes in the pyroelectric coefficient along the [110] direction with temperature. There are large decreases in magnitude of the off-axis pyroelectric coefficient at about $80 \mathrm{~K}, 130 \mathrm{~K}$ and $240 \mathrm{~K}$ (Figure $7 \mathrm{~b}$ ). These temperatures are close to the observed anomalies (Figure 7c) in the elastic stiffness observed at 75, 125 and $215 \mathrm{~K}$ [37]. While the elastic constant $\mathrm{C}_{33}^{\mathrm{D}}$ decreases with decreasing temperature, reaching a minimum at about $75 \mathrm{~K}$, these anomalies in the elasticity have been observed not only along the polar <001> direction, but also along other crystallographic directions, although significantly smaller magnitude [37]. This qualitative agreement between elastic constant anomalies and the magnitude of the off-axis pyroelectric coefficient suggests that the nonzero pyroelectric coefficient observed along the [110] direction is a result of anharmonic dipole oscillations or asymmetric dipole canting. An off-axis pyroelectric effect would not be expected to be as significant when the lattice 
is particularly soft, as may occur in the temperature regions near the elastic stiffness anomalies observed at 75, 125 and $215 \mathrm{~K}$ [37]. This is expected for a secondary pyroelectric effect, where temperature dependent crystal lattice deformations are permitted to occur [5].

Figure 8. The photoemission spectra from $\mathrm{Li}_{2} \mathrm{~B}_{4} \mathrm{O}_{7}(110)$ surface for a succession of temperatures in a heating-cooling cycle (from bottom to top). The photoemission spectra were taken at a photon energy of $56 \mathrm{eV}$ with electrons collected along the surface normal. The measured currents, due to trapped charges, in the [110] direction of lithium tetraborate single crystal with increasing and decreasing temperature (as indicated) in the region of 300 to $600 \mathrm{~K}$ are shown in the inset. Adopted from [5].

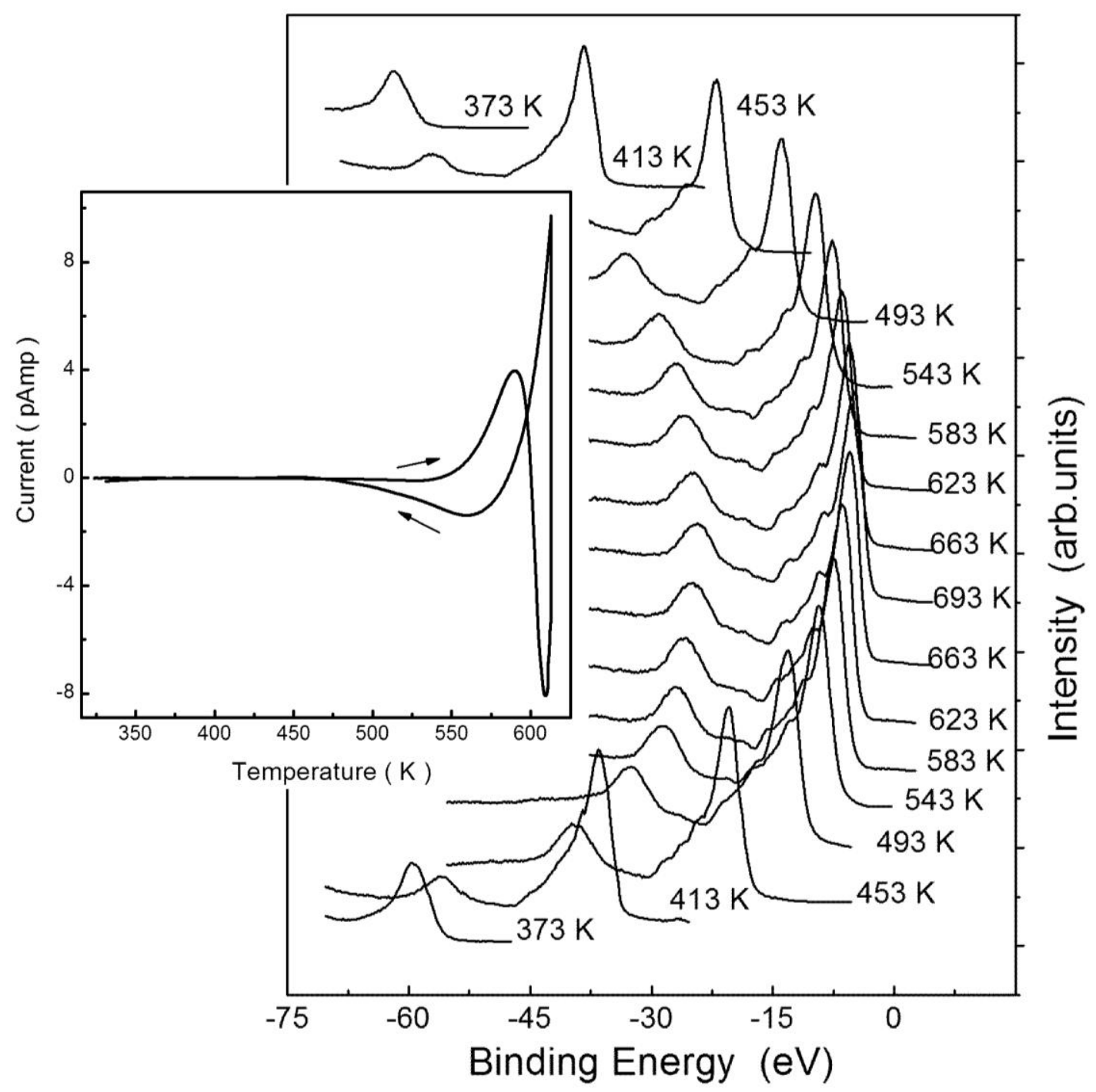

Confirmation of an off-axis pyroelectric effect for much higher temperatures is also evident in the photovoltaic charging. A surface charge or surface electric field might not be possible to measure directly using traditional transport measurements but can be observed in photoemission by exploiting the surface photovoltage effect [5,38-42]. The photovoltage charging, shown in Figure 8 and plotted in Figure 9, regrettably cannot be directly compared with the pyroelectric measurements (Figure 7), as illumination is required and such surface photovoltage measurements 
would tend to work best for a lithium borate surface that is largely defect free [43]. Measurements of the surface charging were essential in any case [5,7,17-18], as the electronic structure measurements reported in the prior section require suppression of surface charging to be a valid measure of electronic structure [7]. We note, in passing, that this is the reason why most of the electronic structure measurements reported in section 2 were done at $623 \mathrm{~K}$, where surface photovoltage charging was found to be negligible [18] and the $\mathrm{Li}_{2} \mathrm{~B}_{4} \mathrm{O}_{7}(110)$ and $\mathrm{Li}_{2} \mathrm{~B}_{4} \mathrm{O}_{7}(100)$ surface exhibited a density of states that qualitatively resembles that expected from the model bulk band structure of $\mathrm{Li}_{2} \mathrm{~B}_{4} \mathrm{O}_{7}[5,7,17-18]$, as seen in Figure 1 .

Figure 9. Photovoltaic charging of $\mathrm{Li}_{2} \mathrm{~B}_{4} \mathrm{O}_{7}(110)$ (red), $\mathrm{Li}_{2} \mathrm{~B}_{4} \mathrm{O}_{7}(100)$ (blue) and $\mathrm{Cu}$ doped $\mathrm{Li}_{2} \mathrm{~B}_{4} \mathrm{O}_{7}(100)$ or $\mathrm{Li}_{1.998} \mathrm{Cu}_{0.002} \mathrm{~B}_{4} \mathrm{O}_{7}(100)$ (black) as measured from the position of the valence band maximum. Spectra were taken, as in Figure 8, with both heating and cooling and the shifts in the valence band maximum recorded in terms of the apparent binding energy with respect to the Femi level E- $\mathrm{E}_{\mathrm{F}}$.

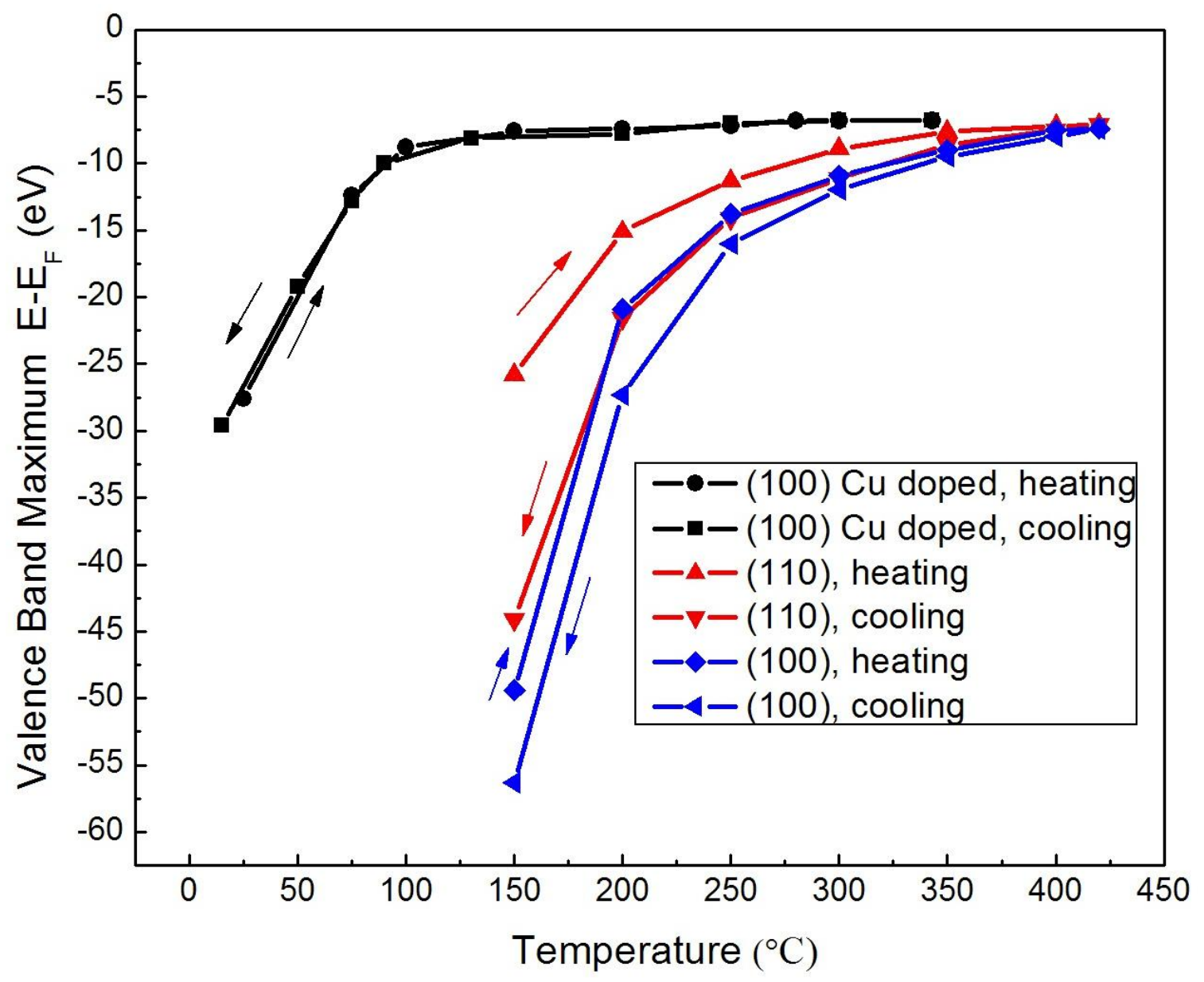

Below $500 \mathrm{~K}$, the surface photo-voltaic charging is both temperature and time dependent, particularly at the (110) surface. There is clearly hysteresis in the photovoltaic charging observed in photoemission. Although the photovoltaic charging is greater for the (100) surface than the (110) surface, the hysteresis is larger for the (110) surface, as determined from the apparent position of the valence band maximum plotted in Figure 9. This hysteresis in the surface 
photovoltaic charging, as measured by the valence band maximum, is consistent with the observation of a pyroelectric current along the (110) direction at the much lower temperatures of 70 to $250 \mathrm{~K}$ (Figure 7). Not all such indications of surface charge accumulation can be considered consistent with pyroelectricity, however.

In the region of $600 \mathrm{~K}$, there is a huge increase in the absolute magnitude of the current with increasing and decreasing temperature, as shown in Figure 8. The currents generated in the region of $600 \mathrm{~K}$ are likely the result of trapped charges or charge trapping point defects [5], with the onset of decreasing or increasing conductivity, respectively, as indicated in the inset to Figure 8 , and may have little to do with the more conventional pyroelectric effect. Indeed, the data suggests trapped charges are released with increasing temperature and charge trapping occurs with decreasing temperature $[5,19]$. The fact that there are two temperature dependent current regimes, in the region of 500 to $600 \mathrm{~K}$, indicates trapped charges may be associated with both lithium and oxygen point defects [19]. The charge trapping or trapped charge release may be the result of ionized defect sites of opposite charge for lithium and oxygen defects, respectively, leading to the generation of currents of opposite sign. This would be expected for oxygen and lithium vacancy defects with different charge trap potentials [5].

\subsection{Evidence for possible surface pyroelectric/piezoelectric effects}

The hysteresis in the photovoltaic charging is not only temperature dependent, but time dependent. The measured effective binding energy $\left(\mathrm{E}-\mathrm{E}_{\mathrm{F}}\right)$, for the oxygen $2 \mathrm{~s}$ shallow core at a binding energy of $-26.0 \pm 0.6 \mathrm{eV}$ at $623 \pm 5 \mathrm{~K}$ (Figure 1), increases (in terms of the absolute value) with decreasing temperature, below $600 \mathrm{~K}$. At temperatures below $500 \mathrm{~K}$, using the oxygen $2 \mathrm{~s}$ shallow core as a benchmark this observed change in binding energy (and associated photovoltaic charging) can be understood as establishment of a steady state surface temperature and surface conductivity. At the (110) surface, there is not only an increase (in terms of the absolute value) in the effective binding energy, but this is followed by a decrease (in terms of the absolute value) in the effective binding energy later in time, as plotted in Figure 10. This latter absolute value decrease in the effective binding energy later in time is observed at the (110) but not the (100) surface (Figure 10) and this time dependent hysteresis effect is increasingly more evident at lower temperatures. As this occurs in a region where there is little or no bulk current, with changes in temperature (Figure 8), this suggests that, while the surface photovoltage effect is initially dominated by the establishment of a steady state surface temperature and surface conductivity, the surface charge density $D_{i}$ is later altered by the local electric field resulting from the surface photovoltage effect. In other words, at the (110) surface, there are time dependent changes in surface charge density $\mathrm{D}_{\mathrm{i}}$. 
Figure 10. The change of the magnitude of the apparent $\mathrm{O} 2 \mathrm{~s}$ binding energy, with time, indicative of the surface photovoltaic charging of the $\mathrm{Li}_{2} \mathrm{~B}_{4} \mathrm{O}_{7}(110)$ surface following a temperature increase to $390 \mathrm{~K}$ compared to the $\mathrm{Li}_{2} \mathrm{~B}_{4} \mathrm{O}_{7}(100)$ surface following a temperature increase to $420 \mathrm{~K}$. Adapted from [5].

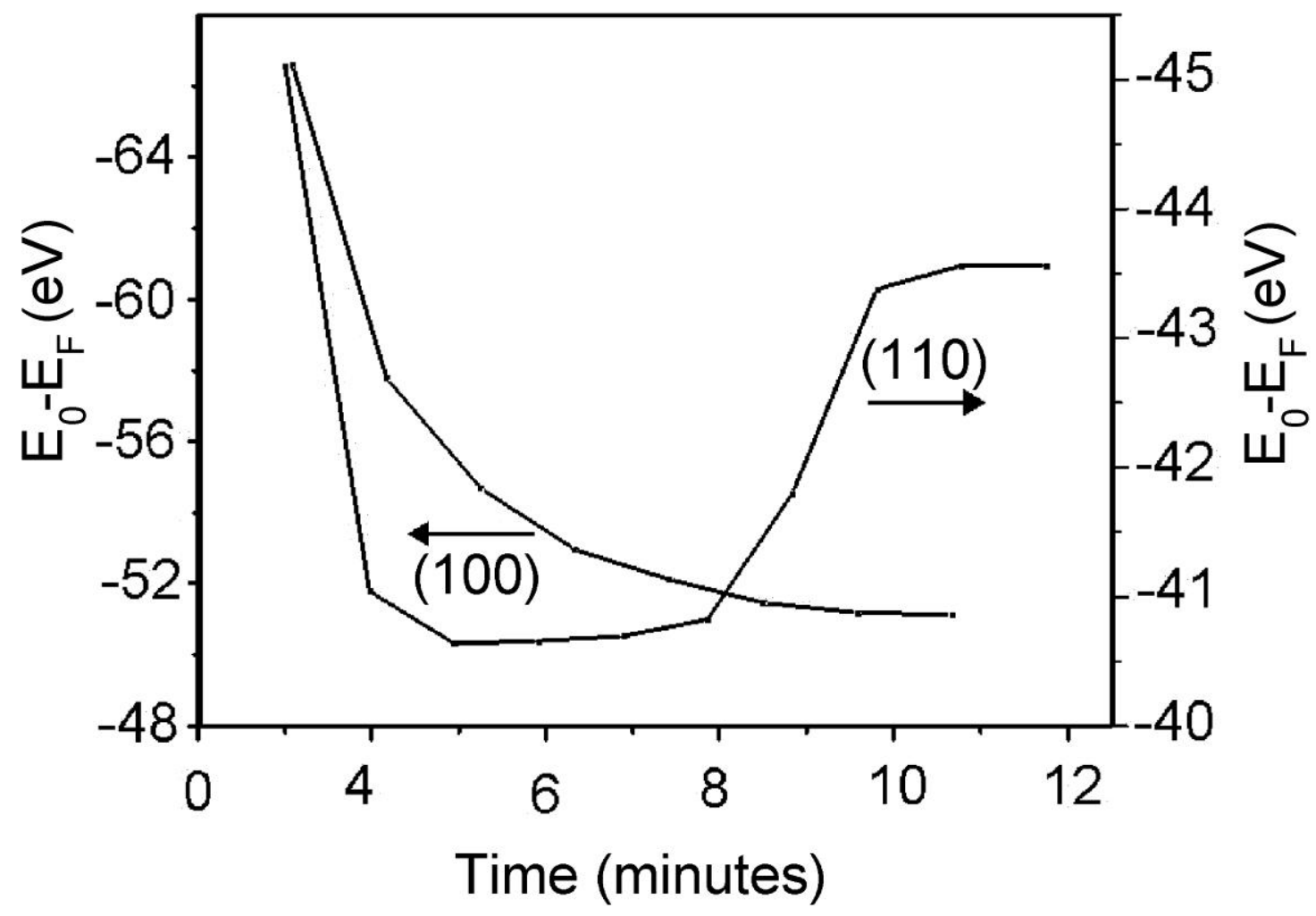

Figure 11. The change in the surface-to-core bulk core level shift with decreasing temperature indicative of differences in the surface photovoltaic charging at the surface and bulk for the $\mathrm{Li}_{2} \mathrm{~B}_{4} \mathrm{O}_{7}(110)$ surface.

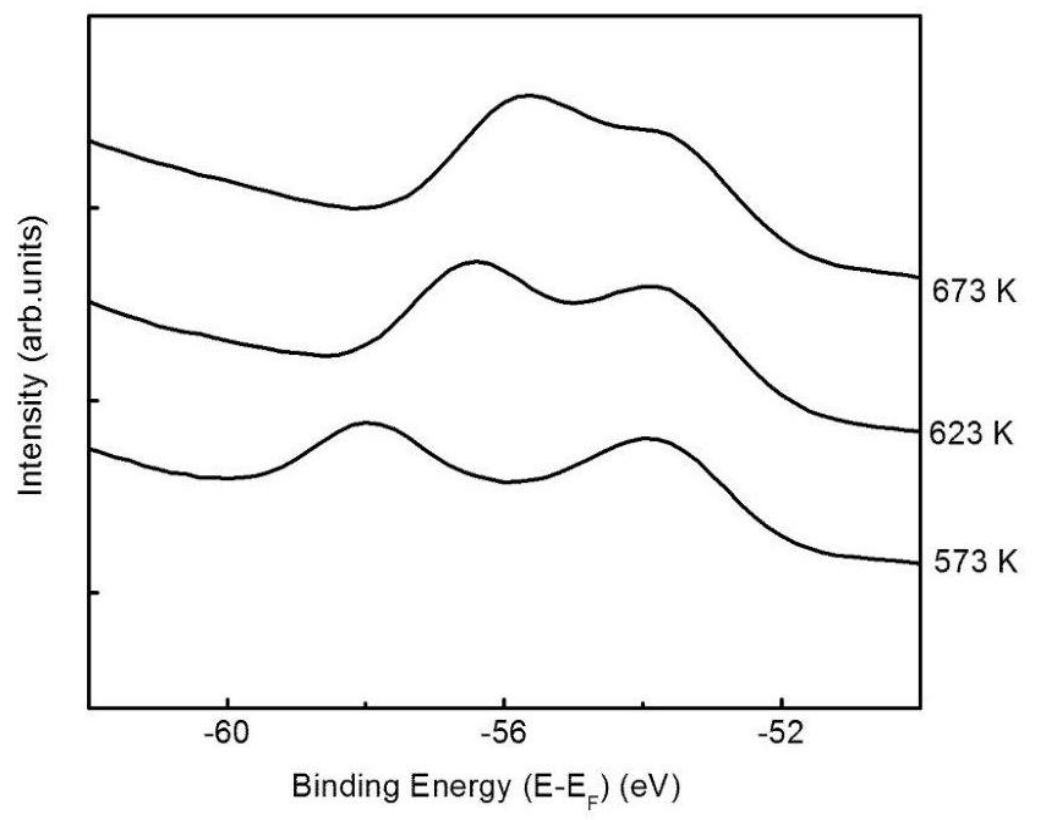


The valence band features and shallow oxygen $2 \mathrm{~s}$ core level shift rigidly together, in apparent binding energies, characteristic of uniform surface photo-voltaic charging in photoemission. This is not the case for the lithium shallow core level. The lithium shallow 1s bulk core level component shifts in binding energy in "lock-step" with the valence band features, with changing temperature, but in the region of $570 \mathrm{~K}$ to $670 \mathrm{~K}$, the surface component of the lithium $1 \mathrm{~s}$ core level, by comparison, shows little evidence of surface photovoltaic charging as indicated in Figure 11. This difference in charging between the surface and bulk components of the Li 1s core level suggests greater conductivity at (110) surface or in the vicinity of the surface lithium sites for temperatures in the region where defect charge trapping occurs, i.e., $623 \pm 5 \mathrm{~K}$. This greater surface conductivity is supported by the luminescence data discussed later. Because of the differences in apparent surface charging at the (110) surface or in the vicinity of the surface lithium sites, a high temperature surface pyroelectric effect in this temperature regime, while unlikely, cannot a priori be excluded. Since the surface is more conductive than the bulk, as suggested by Figure 11, a surface pyroelectric effect must be considered extremely unlikely in the temperature region of 500 to $670 \mathrm{~K}$.

The time dependent hysteresis (Figure 10) is likely a result of a pyroelectric effect leading to a changing surface charge density and charge trapping, as well as possibly an additional surface piezoelectric effect. Certainly, a surface piezoelectric effect can occur at some (but likely not all) surfaces perpendicular to the direction of spontaneous polarization for lithium tetraborate. This too adds credence to the idea [2,5] that the pyroelectric coefficients $p_{\mathrm{i}}$ that include the secondary pyroelectric effect likely have some tensor character and would probably be more accurately expressed as a third order tensor $p_{\mathrm{ijk}}$.

\section{Metal Doping of Lithium Tetraborate}

The undoped $\mathrm{Li}_{2} \mathrm{~B}_{4} \mathrm{O}_{7}$ resistivities are on the order of $10^{10} \Omega \cdot \mathrm{cm}$ [44], but doping could both suppress pyroelectricity and increase transport, ideally electron transport as the hole mass is quite large, as indicated by the band structure [7]. In comparing the photovoltaic charging of the (100) surface termination for $\mathrm{Cu}$ doped and undoped $\mathrm{Li}_{2} \mathrm{~B}_{4} \mathrm{O}_{7}$ (Figure 9), it is clear that doping suppresses not only the surface photovoltaic charging but also hysteresis. While the surface charging at the (100) surface of $\mathrm{Li}_{2} \mathrm{~B}_{4} \mathrm{O}_{7}$ is significantly greater than observed at (110) surface, the $\mathrm{Cu}$ doping plays a role in reducing the surface photovoltage effects. With $\mathrm{Cu}$ doping of $\mathrm{Li}_{2} \mathrm{~B}_{4} \mathrm{O}_{7}$, while the surface photovoltaic charging is much diminished, the density of states observed with combined photoemission and inverse photoemission remains similar to that observed for the undoped material, except in the vicinity of the conduction band edge [45].

The first issues associated with the doping of the $\mathrm{Li}_{2} \mathrm{~B}_{4} \mathrm{O}_{7}$ single crystals to consider are those connected with a valence of impurity and site location in the crystal lattice. In the case of doping by $\mathrm{Cu}$ and $\mathrm{Ag}$ it is also probably very important to take into account the large differences between the impurity ionic radii, i.e., $\mathrm{r}_{\mathrm{Cu}+}=0.96 \AA$ and $\mathrm{r}_{\mathrm{Ag}+}=1.13 \AA$, and the host site radii, $\mathrm{r}_{\mathrm{Li}+}=0.68 \AA$ and $\mathrm{r}_{\mathrm{B} 3+}=0.16 \AA$. There is no guarantee that a dopant impurity ion $\mathrm{Ag}^{+}$will occupy a $\mathrm{B}^{3+}$ ion site and much to suggest it will not, because of the large difference in ionic radii, as well as differences in valence. 
Generally, electron paramagnetic resonance (EPR) and electron-nuclear double resonance (ENDOR) studies in $\mathrm{Li}_{2} \mathrm{~B}_{4} \mathrm{O}_{7}$ have focused on $\mathrm{Cu}^{+}[15,19,46-47], \mathrm{Co}^{2+}$ and $\mathrm{Mn}^{2+}$ [48-49], impurities substituting for lithium and vacancy-related defects produced by neutron irradiation at room temperature. The $\mathrm{Cu}$ impurity centers in the $\mathrm{Li}_{2} \mathrm{~B}_{4} \mathrm{O}_{7}$ lattice generally adopt the univalent $\mathrm{Cu}^{+}$ion state [46-47,50,51-54], independent of the valence of the initial chemical copper source additive agent used for $\mathrm{Cu}$ doping.

Copper impurity ions substitute for lithium ions in the $\mathrm{Li}_{2} \mathrm{~B}_{4} \mathrm{O}_{7}$ lattice [19,46-47,50,51-54], with most of them being in the monovalent charge state prior to the X-ray irradiation. Heating above room temperature restores the pre-irradiation distribution of copper charge states. Indeed, thermoluminescence data indicates that the recombination process $\mathrm{Cu}^{2+}+\mathrm{e}$ to $\mathrm{Cu}^{1+}+\mathrm{h} v$ occurs in the region of $362 \mathrm{~K}$ or less [46]. These ground state $\mathrm{Cu}^{+}\left(3 \mathrm{~d}^{10}\right)$ impurity ions convert to $\mathrm{Cu}^{2+}\left(3 \mathrm{~d}^{9}\right)$ ions during the irradiation as they trap "free" holes from the valence band [19] or (alternatively) the electron of the $\mathrm{Cu}^{2+}$ exciton resides in the nearest appropriate lattice defect site [46]. The $\mathrm{Cu}$ impurities are extremely robust and stable in the $1+$ state, even in the nominally $\mathrm{Li}_{1.998} \mathrm{Cu}_{0.002} \mathrm{~B}_{4} \mathrm{O}_{7}$, both as-grown [19,46-47,50,51-54] as well as after irradiation at room temperature with X-rays [50].

It is possible that the $\mathrm{Cu}$ atoms occupying the $\mathrm{Li}$ sites will act as donors [45] and a more heterogeneous distribution of donor sites would account for the more gradual increase in the conduction band edge density of state away from the Fermi level seen in the inverse photoemission [45]. If either the surface or bulk donor state density increases with $\mathrm{Cu}$ doping then the surface photovoltaic charging should diminish compared to the undoped $\mathrm{Li}_{2} \mathrm{~B}_{4} \mathrm{O}_{7}(100)$ surfaces, as is observed.

If the $\mathrm{Cu}$ impurities actually increase the number of hole traps, then, in spite of the heavy hole mass expected from the band structure [7], the resulting decrease in hole carrier mobilities should decrease the conductivity. There is also the possibility that the $\mathrm{Cu}^{1+}$ impurity ion traps an electron to go to a transient $\mathrm{Cu}^{0}$ state, as suggested by the thermoluminescence [46] and cathodoluminescence [55-56] of $\mathrm{Li}_{2} \mathrm{~B}_{4} \mathrm{O}_{7}$ : $\mathrm{Cu}$. If either process occurs with appreciable probability at the surface as well, then the surface photovoltaic charging should increase compared to the undoped $\mathrm{Li}_{2} \mathrm{~B}_{4} \mathrm{O}_{7}(100)$ surfaces.

Can these impurity states, introduced by dopants, be observed more directly?

\subsection{Optical properties}

$\mathrm{Li}_{2} \mathrm{~B}_{4} \mathrm{O}_{7}$ single crystals are transparent in the range of $165-6000 \mathrm{~nm}$ and the fundamental absorption maximum is placed at about $133 \mathrm{~nm}$ [57]. The transmission spectra [50] of the undoped as well as $\mathrm{Cu}$ and $\mathrm{Ag}$ doped $\mathrm{Li}_{2} \mathrm{~B}_{4} \mathrm{O}_{7}$ single crystals are shown in Figure 12. The values of the direct optical band gap energy of undoped $\mathrm{Li}_{2} \mathrm{~B}_{4} \mathrm{O}_{7}$ obtained by extrapolation of the absorption coefficient to zero absorption in the $\mathrm{k}^{2}=\mathrm{f}(\mathrm{h} v)$ plot was $\mathrm{E}_{\mathrm{g}}(\mathrm{opt})=7.4 \mathrm{eV}[15,50]$, somewhat less than the band gap of $9.8 \pm 0.5 \mathrm{eV}$ (with a range from $8.9 \pm 0.5 \mathrm{eV}$ to $10.1 \pm 0.5 \mathrm{eV}$ ) obtained from the combined photoemission and inverse photoemission [7], as discussed previously .

For the undoped and $\mathrm{Cu}$ and $\mathrm{Ag}$ doped $\mathrm{Li}_{2} \mathrm{~B}_{4} \mathrm{O}_{7}$ single crystals, the transmission spectra do not include any absorption bands in the range of 900-300 nm [50], at a temperature of $290 \mathrm{~K}$. For $\mathrm{Li}_{2} \mathrm{~B}_{4} \mathrm{O}_{7}: \mathrm{Cu}$, the transmission spectrum (Figure 12, curve 2) exhibits a broad low-intensity band in 
300-167 nm region at a temperature of $290 \mathrm{~K}$ [52]. With $\mathrm{Ag}$ impurities in $\mathrm{Li}_{2} \mathrm{~B}_{4} \mathrm{O}_{7}$, two intensive absorption bands can be observed near the characteristic absorption edge of the $\mathrm{Li}_{2} \mathrm{~B}_{4} \mathrm{O}_{7}$, namely at 205 and $174 \mathrm{~nm}$ (Figure 12, curve 3) [50].

Figure 12. The transmission spectra of $\mathrm{Li}_{2} \mathrm{~B}_{4} \mathrm{O}_{7}$ single crystals at a temperature of $290 \mathrm{~K}$ : 1 - undoped; 2 - Cu doped; 3-Ag doped. Adapted from [50].

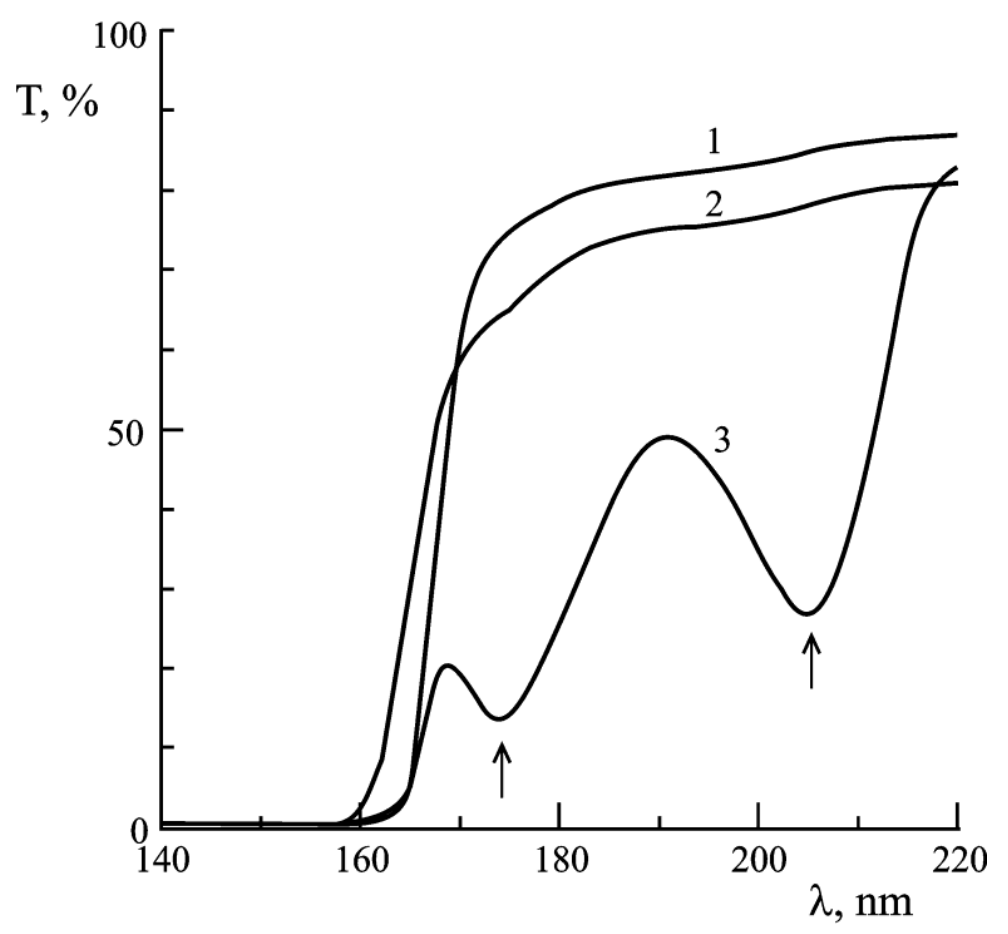

For the case of $\mathrm{Li}_{2} \mathrm{~B}_{4} \mathrm{O}_{7}$ : $\mathrm{Cu}$ single crystals, the absorption bands of $\mathrm{Cu}^{+}$ions lying near $5 \mathrm{eV}$ correspond to the $3 \mathrm{~d}^{10} \rightarrow 3 \mathrm{~d}^{9} 4 \mathrm{~s}$ electron transitions. For $\mathrm{Li}_{2} \mathrm{~B}_{4} \mathrm{O}_{7}: \mathrm{Ag}$ single crystals, the corresponding adsorption transition for the $\mathrm{Ag}^{+}$ions is $4 \mathrm{~d}^{10} \rightarrow 4 \mathrm{~d}^{9} 5 \mathrm{~s}$. But variations can occur due to the splitting of these levels caused by the crystal field. In free $\mathrm{Cu}^{+}$and $\mathrm{Ag}^{+}$ions, these transitions are generally considered symmetry or parity forbidden, but they can take place in many crystals, like $\mathrm{Li}_{2} \mathrm{~B}_{4} \mathrm{O}_{7}$, due to symmetry breaking as a result of odd symmetry (transverse optical) vibrations of the crystal lattice. The absorption bands due to the $\mathrm{Cu}^{+}$ions in $\mathrm{Li}_{2} \mathrm{~B}_{4} \mathrm{O}_{7}$ exist in sites surrounded by deformed octahedral oxygen. Octahedral oxygen environment is consistent with the evidence, discussed above, that $\mathrm{Cu}^{+}$ions are located at specific locations within the $\mathrm{Li}_{2} \mathrm{~B}_{4} \mathrm{O}_{7}$ crystal lattice, and not at random interstitial sites. With a substitution of $\mathrm{Li}^{+}$ion sites, the oxygen environment about the $\mathrm{Cu}^{+}$ions must be a deformed tetrahedron [46].

On the basis of the results of the thermoluminescence, X-ray luminescence and absorption spectroscopy studies (Figure 13) of $\mathrm{Li}_{2} \mathrm{~B}_{4} \mathrm{O}_{7}: \mathrm{Cu}$, and $\mathrm{Li}_{2} \mathrm{~B}_{4} \mathrm{O}_{7}: \mathrm{Ag}$ single crystals, some of us [50] have proposed a mechanism for the formation of $\mathrm{A}^{0}\left(\mathrm{Cu}^{0}\right.$ or $\left.\mathrm{Ag}^{0}\right)$ centers of luminescence with the participation of growth defects. The $\mathrm{A}^{0}$ centers play a dominant part in the accumulation of the light yield under irradiation. The luminescence occurs by means of the energy transfer to a self-trapped exciton in the $\mathrm{Li}_{2} \mathrm{~B}_{4} \mathrm{O}_{7}$, crystal lattice followed by radiative decay (annihilation) [50]. Thus, the luminescence scheme in $\mathrm{Li}_{2} \mathrm{~B}_{4} \mathrm{O}_{7}: \mathrm{Cu}, \mathrm{Ag}$ single crystals can be represented as follows: 


$$
\begin{aligned}
\mathrm{Li}_{2} \mathrm{~B}_{4} \mathrm{O}_{7}: \mathrm{A}^{+} \rightarrow \text { Irradiated } & \rightarrow \mathrm{Li}_{2} \mathrm{~B}_{4} \mathrm{O}_{7}:\left(\mathrm{A}^{0}+\mathrm{h}\right) \rightarrow \text { Heat } \rightarrow \mathrm{Li}_{2} \mathrm{~B}_{4} \mathrm{O}_{7}:\left(\mathrm{A}^{+}+\mathrm{STE}\right) \rightarrow \\
& \rightarrow \text { Annihilation } \rightarrow \mathrm{Li}_{2} \mathrm{~B}_{4} \mathrm{O}_{7}: \mathrm{A}^{+}+\mathrm{h} v
\end{aligned}
$$

Figure 13. The thermoluminescence spectrum of $\mathrm{Li}_{2} \mathrm{~B}_{4} \mathrm{O}_{7}: \mathrm{Cu}$ and $\mathrm{Li}_{2} \mathrm{~B}_{4} \mathrm{O}_{7}: \mathrm{Ag}$ single crystals after $\mathrm{X}$-irradiation, obtained for the $150 \mathrm{~K}$ peak, from [50].

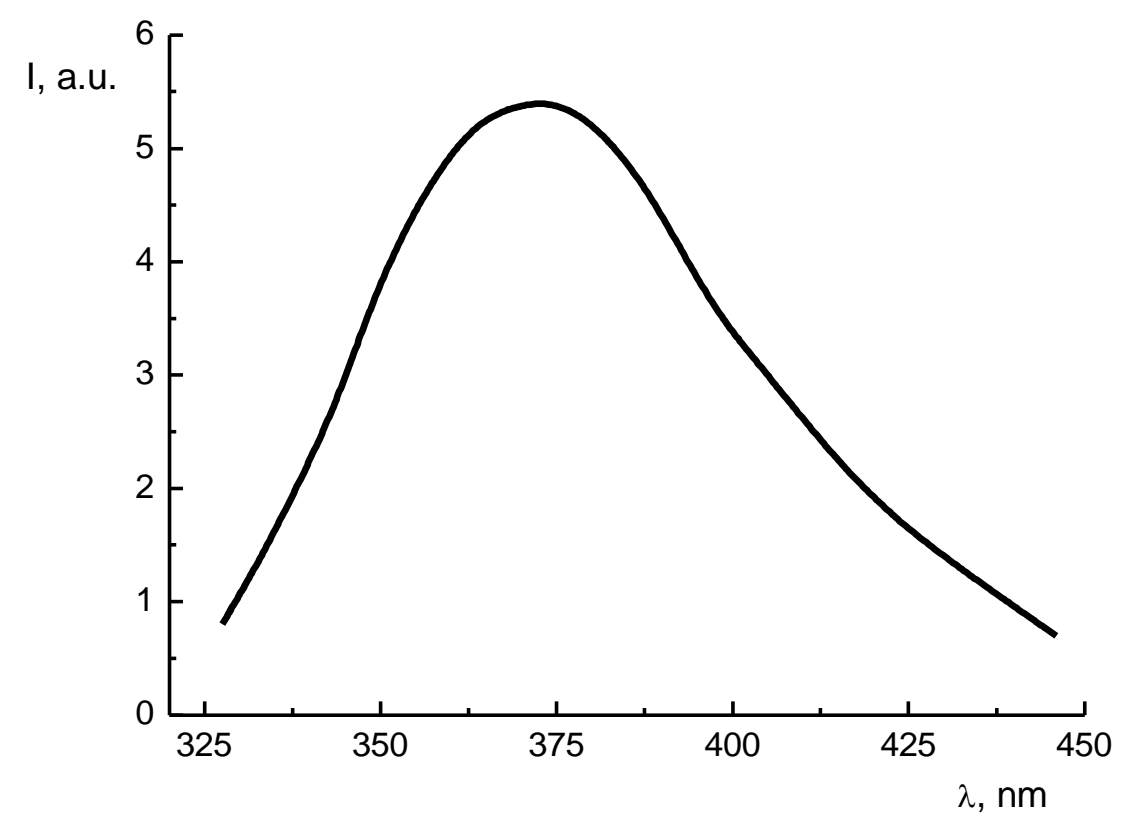

It is useful to compare the cathodoluminescence spectra of $\mathrm{Li}_{2} \mathrm{~B}_{4} \mathrm{O}_{7}: \mathrm{Cu}$ with other luminescence spectra such as X-ray luminescence, photoluminescence, radioluminescence, and especially thermoluminescence. As shown in Figure 14, the cathodoluminescence spectrum of undoped $\mathrm{Li}_{2} \mathrm{~B}_{4} \mathrm{O}_{7}$ single crystals, taken at $295 \mathrm{~K}$, has a maximum at $3.65 \mathrm{eV}(340 \mathrm{~nm})$, but contains contributions from a luminescence band at $2.2 \mathrm{eV}(564 \mathrm{~nm})$. These cathodoluminescence spectra are very similar to the radioluminescence [58], X-ray luminescence spectra at $293 \mathrm{~K} \mathrm{[57]} \mathrm{and} \mathrm{to}$ some extent similar with the thermoluminescence spectrum [46].

We find the cathodoluminescence spectrum of $\mathrm{Li}_{2} \mathrm{~B}_{4} \mathrm{O}_{7}: \mathrm{Cu}$ single crystals $(0.015$ at. $\% \mathrm{Cu})$ does, however, differ slightly from the luminescence spectra obtained by other excitation mechanisms. For example, the cathodoluminescence spectrum maximum, at $295 \mathrm{~K}$ (Figure 14b) is at $3.50 \mathrm{eV}$ $(355 \mathrm{~nm})$. For other types of luminescence, the excitations tend to occur in a region near $3.35 \mathrm{eV}$ $(370 \mathrm{~nm})$ [46,50,59-61] and the shape of the luminescence spectra can differ drastically. In the case of $\mathrm{Li}_{2} \mathrm{~B}_{4} \mathrm{O}_{7}: \mathrm{Cu}$, the superposition of some luminescence bands in the cathodoluminescence spectra can be clearly seen: components with maxima at $3.40 \mathrm{eV}(365 \mathrm{~nm})$ and $3.55 \mathrm{eV}(350 \mathrm{~nm})$ (Figure 14b). Overall, analysis of all the cathodoluminescence spectra provides compelling evidence that the luminescence band of $\mathrm{Li}_{2} \mathrm{~B}_{4} \mathrm{O}_{7}$ is connected with self-trapped excitons near crystal defects [57,62-63].

\subsection{Carrier lifetimes}

The carrier lifetimes or the decay times $\tau$ are important for the understanding of the role of dopants like $\mathrm{Cu}$ in the suppression of the surface voltaic charging. The cathodoluminescence line 
widths, which include a strong surface component, suggest that electron lifetime is, in fact, much longer for the $\mathrm{Li}_{2} \mathrm{~B}_{4} \mathrm{O}_{7}: \mathrm{Cu}$ single crystals than the undoped $\mathrm{Li}_{2} \mathrm{~B}_{4} \mathrm{O}_{7}$ single crystals [55]. This may be taken as strong evidence of the very real possibility of an increase in surface and, possibly, bulk conductivity with copper doping. The broad band photoluminescence was observed for undoped $\mathrm{Li}_{2} \mathrm{~B}_{4} \mathrm{O}_{7}$ crystals, with photo-excitation above $7.5 \mathrm{eV}$, and the decay luminescence consists of two components with time constants $\tau<1 \mathrm{~ns}$ and $\tau \sim 8.5 \mathrm{~ns}$, as well as a slow component in the microsecond time range [64]. The emission at $3.35 \mathrm{eV}$ arising from the $\mathrm{Cu}^{+}$ion $3 \mathrm{~d}^{9} 4 \mathrm{~s} \rightarrow 3 \mathrm{~d}^{10}$ transitions in $\mathrm{Li}_{2} \mathrm{~B}_{4} \mathrm{O}_{7}: \mathrm{Cu}$ single crystals, with 5 and $7 \mathrm{eV}$ photoexcitation, has a decay time of 25 $\mu \mathrm{s}$, at $297 \mathrm{~K}$ [65]. Our estimations of the $\tau$ parameter for the slow component decay time of the cathodoluminescence [55] is $\tau>300 \mathrm{~ns}$ for undoped crystals and $\tau>50 \mu$ s for doped $\mathrm{Li}_{2} \mathrm{~B}_{4} \mathrm{O}_{7}$ : $\mathrm{Cu}$ crystals.

This difference between the decay time of $25 \mu$ s seen with photoluminescence and a decay time $\tau>50 \mu$ s observed in cathodoluminescence for $\mathrm{Li}_{2} \mathrm{~B}_{4} \mathrm{O}_{7}: \mathrm{Cu}$ crystals means that secondary charge carriers, both electrons and holes ( $e$ and $h$ ), are free to move for some time at the surface of $\mathrm{Li}_{2} \mathrm{~B}_{4} \mathrm{O}_{7}: \mathrm{Cu}$ single crystals. If we accept the mean free lifetime of the secondary charge carriers is $\tau=50 \mu$ s and the effective electron mass is $\mathrm{m} * / \mathrm{m}_{\mathrm{e}}=0.15$ [18], then the mobility may be estimated to be $\mu=\mathrm{e} \tau / \mathrm{m}^{*}=1.8 \times 10^{14} \mathrm{~cm}^{3 / 2} \cdot \mathrm{g}^{-1 / 2}$. Because of the very light mass image state $\mathrm{m}^{*} / \mathrm{m}_{\mathrm{e}}=0.06$ [18], the surface mobility may be estimated to be even larger, at about $\mu=\mathrm{e} \tau / \mathrm{m}^{*}=4.4 \times 10^{14} \mathrm{~cm}^{3 / 2} \cdot \mathrm{g}^{-1 / 2}$.

Figure 14. Cathodoluminescence spectra at $295 \mathrm{~K}_{\text {of }} \mathrm{Li}_{2} \mathrm{~B}_{4} \mathrm{O}_{7}$ single crystals undoped (a) and doped with $\mathrm{Cu}(0.015 \%)$ (b). Adapted from [55].
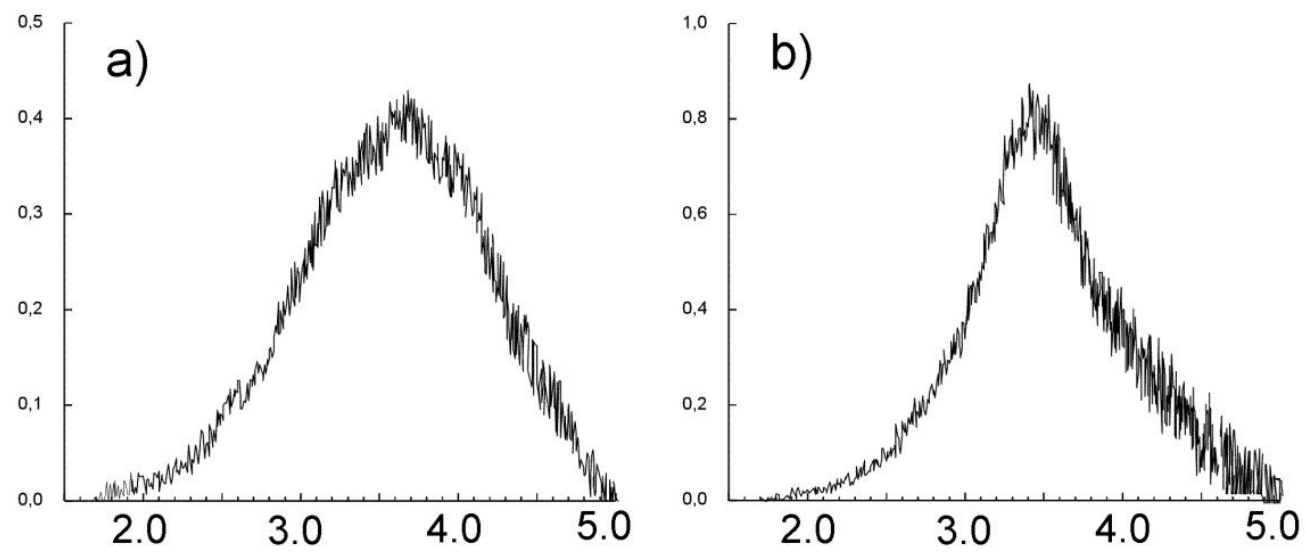

Photon Energy (eV)

This enhanced carrier mobility at the surface is consistent with the generally greater surface conductivity evident in the surface photovoltaic charging, as discussed above. The increased surface mobilities and carrier lifetimes, we infer from cathodoluminescence, such as occur with $\mathrm{Cu}$ doping, certainly explain the quenching of the hysteresis in the surface photovoltage seen at the surfaces of undoped $\mathrm{Li}_{2} \mathrm{~B}_{4} \mathrm{O}_{7}(100)$ and $\mathrm{Li}_{2} \mathrm{~B}_{4} \mathrm{O}_{7}(110)$, as evident in Figure 9. 


\section{Experimental Section}

In nature, $\mathrm{Li}_{2} \mathrm{~B}_{4} \mathrm{O}_{7}$ occurs as a clear, colorless mineral as inclusions of diomignite in pegmatite [66]. Sastry and Hummel were the first [67] to crystallize lithium tetraborate $\left(\mathrm{Li}_{2} \mathrm{~B}_{4} \mathrm{O}_{7}\right)$ from a congruent melt. Single crystals of $\mathrm{Li}_{2} \mathrm{~B}_{4} \mathrm{O}_{7}$ were first grown by Garrett and coworkers [68]. The $\mathrm{Li}_{2} \mathrm{~B}_{4} \mathrm{O}_{7}$ single crystals used here were grown from the melt by the Czochralski technique as described elsewhere [15,69]. The [110] and [100] crystals have been cut with a miscut of no more than $0.5^{\circ}$, as determined by $\mathrm{X}$-ray diffraction $[5,11]$. The pyroelectric measurements along the [110] and [100] directions were performed in a manner similar to prior studies [25-26] over a range of heating rates from 0.015 to $0.4 \mathrm{~K} / \mathrm{sec}$, as described elsewhere [5]. At the lowest temperatures $(50-70 \mathrm{~K})$, the heating and cooling rates deviate from the linear, and these deviations have been taken into account in the analysis. Regardless, variations in the heating rate from experiment to experiment were not found to significantly alter the measured pyroelectric coefficients [5].

The temperature dependent angle-resolved photoemission spectra were obtained using linearly polarized synchrotron light dispersed by a $3 \mathrm{~m}$ toroidal grating monochromator [7,17-18,70-71], at the Center for Advanced Microstructures and Devices (CAMD) [72]. The measurements were made in an ultra-high vacuum (UHV) chamber employing a hemispherical electron analyzer with an angular acceptance of $\pm 1^{\circ}$, as described elsewhere [70-71]. The photoemission experiments were undertaken with a light incidence angle of $45^{\circ}$ with respect to the surface normal, unless stated otherwise. The photoelectrons were collected along the surface normal throughout. The photoemission was conducted over a range of temperatures from 250 to $700 \mathrm{~K}$, but the binding energies are referenced to the Fermi level established at temperatures greater than $623 \mathrm{~K}$, where surface charging was found to be negligible [5,7,17-18]. The location of the Fermi level was determined via angle-resolved photoemission using tantalum films in electrical contact with the samples [5,7,17-18]. The inverse photoemission was conducted in a separate vacuum system, as described elsewhere [7,20], with a k-resolved band mapping of the unoccupied levels obtained by changing the incidence angle.

The reference of the observed binding energies to the Fermi level for $\mathrm{Li}_{2} \mathrm{~B}_{4} \mathrm{O}_{7}(110)$, as done here, differs from the sometimes common practice of assigning binding energies with respect to the valence band maximum for lithium tetraborate [14]. Prior studies of lithium tetraborate also have assigned their binding energies with respect to the chemical potential or Fermi level [73]. We chose the latter convention for this investigation, i.e., citing binding energies in terms of $\mathrm{E}-\mathrm{E}_{\mathrm{F}}$.

In the photoemission experiments, after various combinations of argon ion sputtering and annealing, the surface was found to be ordered, stoichiometric and free of contamination. The surface ordering was confirmed by the presence of a dispersing ( $\mathrm{E}$ versus $\mathrm{k}_{\|}$dependent) band structure in angle-resolved inverse photoemission with the critical points that match the expected surface periodicity. The absence of surface contamination at the $\mathrm{Li}_{2} \mathrm{~B}_{4} \mathrm{O}_{7}(110)$ surface prepared for the temperature dependent photoemission studies is evident in the photoemission spectra taken at higher photon energies [5,7,17] and from clear evidence of a light mass image state [7] in the angle-resolved inverse photoemission. Although the unoccupied band structure of $\mathrm{Li}_{2} \mathrm{~B}_{4} \mathrm{O}_{7}(110)$ surface, mapped out in inverse photoemission [7], is consistent with the lattice constants of the 
(110) surface, reconstructions of the surface cannot be excluded. Because of the extremely dielectric nature of these crystals, low energy electron diffraction intensity versus voltage I(V) surface structural analysis was not possible in the temperature range where the pyroelectric currents were most evident (well below room temperature).

While the X-ray diffraction shows that the material is well oriented and single phase, electron paramagnetic resonance (EPR) and electron-nuclear double resonance (ENDOR) revealed three different point defects in the undoped crystals [19]. From greatest amount to least, these different defects were isolated oxygen vacancies, isolated lithium vacancies, and a trace of $\mathrm{Cu}$ impurities. These isolated point defects, amounting to between 2 and $5 \mathrm{ppm}$ in total, were not sufficient to degrade the dielectric properties of our crystals, and there was insufficient current to observe any power law conductivity. Indeed very little current was generated with intense neutron irradiation of $\mathrm{Li}_{2} \mathrm{~B}_{4} \mathrm{O}_{7}$ crystals enriched to 95 at $\%{ }^{6} \mathrm{Li}$ and 97.3 at $\%{ }^{10} \mathrm{~B}$ (isotopes with very high neutron capture cross-section) at more than $500 \mathrm{~V}$ applied bias, indicating very little dark current is possible in $\mathrm{Li}_{2} \mathrm{~B}_{4} \mathrm{O}_{7}$ crystals with natural abundance of $\mathrm{Li}$ and $\mathrm{B}$, in the absence of irradiation or illumination, as is the case in the crystals studied here.

Cathodoluminescence of the $\mathrm{Li}_{2} \mathrm{~B}_{4} \mathrm{O}_{7}$ and $\mathrm{Li}_{2} \mathrm{~B}_{4} \mathrm{O}_{7}: \mathrm{Cu}$ samples was performed at room temperature in the pulsed regime (with a pulse duration of $3 \mu$ s with repetition rate of $20 \mathrm{~Hz}$ ). The energy of electron beam was $9.5 \mathrm{keV}$, the current in the beam was $200 \mu \mathrm{A}$, the diameter of electron beam on the sample was $1 \mathrm{~mm}$, and the angle of incidence on the sample surface was $30^{\circ}$. The depth of electron penetration can be calculated according to the empirical formula [74,75]:

$$
R=\frac{2.76 \times 10^{-2} A U^{5 / 3}}{\rho Z^{8 / 9}} \cos 30^{\circ}(\mu \mathrm{m})
$$

where $Z$ it the effective atomic number, $A$ is the effective atomic weight appropriate to the effective $Z, U$ the accelerating voltage, and $\rho$, density. For $\mathrm{Li}_{2} \mathrm{~B}_{4} \mathrm{O}_{7}$ crystals, where $Z=7.3, A=12$, $\rho=2.44 \mathrm{~g} / \mathrm{cm}^{3}$, the penetration depth $R$ of electrons under an accelerating voltage of $9.5 \mathrm{kV}$ and at the angle of incidence of $30^{\circ}$ does not exceed $0.85 \mu \mathrm{m}$.

\section{Conclusions}

We find a pyroelectric current and hysteresis in the surface photovoltaic charging along the [110] direction of stoichiometric $\mathrm{Li}_{2} \mathrm{~B}_{4} \mathrm{O}_{7}$. The pyroelectric coefficient is roughly $10^{3}$ smaller than along the [001] direction of spontaneous polarization but nonzero. Abrupt decreases in the pyroelectric coefficient along the [110] direction can be correlated with anomalies in the elastic stiffness $\mathrm{C}_{33}^{\mathrm{D}}$ contributing to the concept that the pyroelectric coefficient is not simply a vector but has qualities of a tensor, as expected. The concept of a secondary pyroelectric effect, considered as a very real possibility for decades [2], has now been conclusively demonstrated in at least one pyroelectric material.

The time dependent surface photovoltaic charging suggests that pyroelectric and piezoelectric effects that occur at the (110) surface may be more significant than those that occur at the (100) surface. These effects are complicated by the fact that the surface conductivity may well differ 
significantly from the bulk due to a light mass image state at the (110) surface, leading to the enhanced surface carrier mobilities at elevated temperatures.

As with all piezoelectric materials, lithium tetraborate is a dielectric, but pyroelectricity is suppressed with $\mathrm{Cu}$ doping. It should be noted that because of the very light electron mass, compared to the heavy hole mass, as abstracted from the experimental band structure, it is clear that excitations leading to electron-hole pair creation are unlikely to lead to complete charge collection on a short time scale. This will also apply to current generated by electron-hole pair creation generated by ${ }^{6} \mathrm{Li}$ or ${ }^{10} \mathrm{~B}$ nuclei neutron capture (with large cross-sections for thermal neutrons), although currents have been measured as a result of neutron irradiation for some lithium borates $[44,76]$. While the asymmetry between electron and hole carrier mobilities is tied to the band structure, carrier lifetimes are seen to increase by a factor of more than 150 with doping, and thus doping could lead to improved charge collection with excitation spectroscopies.

\section{Acknowledgements}

This work was supported by the Defense Threat Reduction Agency (Grant No. HDTRA1-07-1-0008 and BRBAA08-I-2-0128), the NSF through NSF/CHE-Analytical and Surface Chem. CHE- 0909580 and the "QSPINS" MRSEC (DMR-0820521) at UNL, the Ministry of Education and Sciences of Ukraine Project 0109 U001063 and STCU Project 4947. The authors would like to thank Shan Yang (杨山) and L.E. Halliburton for technical support and insights into the EPR spectra and thank Alexei Gruverman for a number of helpful discussions. The views expressed in this article are those of the authors and do not reflect the official policy or position of the Air Force, Department of Defense or the U.S. Government.

\section{References}

1. Lang, S.B. Pyroelectricity: From ancient curiosity to modern. Phys. Today 2005, 58, 31.

2. Nye, J.F. Physical Properties of Crystals; Oxford University: Oxford, UK, 1957 and 1985; Chapter 10, pp. 171-191.

3. Damjanovic, D. Ferroelectric, dielectric and piezoelectric properties of ferroelectric thin films and ceramics. Rept. Prog. Phys. 1998, 61, 1267-1324

4. Wu, C.G.; Zhang, W.L.; Li, Y.R.; Liu, Z.; Zhu, J. Measurement of induced pyroelectric coefficient using dynamic method: Theory and experiments. Jpn. J. Appl. Phys. 2006, 45, 2674-2677.

5. Ketsman, I.; Wooten, D.; Xiao, J.; Losovyj, Y.B.; Burak, Y.V.; Adamiv, V.T.; Sokolov, A.; Petrosky, J.; McClory, J.; Dowben, P.A. The off-axis pyroelectric effect observed for lithium tetraborate. Phys. Lett. A 2010, 374, 891-895.

6. Shur, V.Ya.; Gruverman, A.L.; Zalyuk, S.B. Ferroelectrics and Piezoelectrics; Gruvermann, A. Private communication, 1989, 81-85.

7. Wooten, D.; Ketsman, I.; Xiao, J.; Losovyj, Ya.B.; Petrosky, J.; McClory, J.; Burak, Ya.V.; Adamiv, V.T.; Brown J.M.; Dowben, P.A. The electronic structure of $\mathrm{Li}_{2} \mathrm{~B}_{4} \mathrm{O}_{7}(110)$ and $\mathrm{Li}_{2} \mathrm{~B}_{4} \mathrm{O}_{7}(100)$. Eur. J. Phys.-Appl. Phys. 2010, in press. 
8. Krogh-Moe, J. The crystal structure of lithium diborate, $\mathrm{Li}_{2} \mathrm{O} \cdot 2 \mathrm{~B}_{2} \mathrm{O}_{3}$. Acta Crystallogr. 1962, 15, 190-193.

9. Krogh-Moe, J. Refinement of the crystal structure of lithium diborate, $\mathrm{Li}_{2} \mathrm{O} \cdot 2 \mathrm{~B}_{2} \mathrm{O}_{3}$. Acta Crystallogr. 1968, 24, 179-181.

10. Natarajan, M.; Faggiani, R.; Brown, I.O. Dilithium tetraborate, $\mathrm{Li}_{2} \mathrm{~B}_{4} \mathrm{O}_{7}$. Cryst. Struct. Commun. 1979, 8, 367-370.

11. Radaev, S.V.; Muradyan, L.A.; Malakhova, L.F.; Burak, Ya.V.; Simonov, V.I. Atom structure and electron dencity of the lithium tetraborate $\mathrm{Li}_{2} \mathrm{~B}_{4} \mathrm{O}_{7}$. Sov. Phys. Crystallgr. 1989, 34, 842-849.

12. Burak, Y.V.; Padlyak, B.V.; Shevel, V.M. Neutron-induced defects in lithium tetraborate single crystals. Radiat. Eff. Defect. Solid. 2002, 157, 1101-1109.

13. Adamiv, V.T.; Burak, Ya.V.; Teslyuk, I.M. Growth and properties of new nonlinear $\mathrm{LiKB}_{4} \mathrm{O}_{7}$ single crystals. J. Crys. Growth 2006, 289, 157-160.

14. Islam, M.M.; Maslyuk, V.V.; Bredow, T.; Minot, C. Structural and electronic properties of $\mathrm{Li}_{2} \mathrm{~B}_{4} \mathrm{O}_{7}$. J. Phys. Chem. 2005, B109, 13597-13604.

15. Adamiv, V.T.; Burak, Ya.V.; Kityk, I.V.; Kasperczyk, J.; Smok, R.; Czerwinski, M. Nonlinear optical properties of $\mathrm{Li}_{2} \mathrm{~B}_{4} \mathrm{O}_{7}$ single crystals doped with potassium and silver. Opt. Mater. 1997, 8, 207-213.

16. Burak, Ya.V.; Dovgyi, Ya.O.; Kityk, I.V. The energy band structure and chemical bonds in $\mathrm{Li}_{2} \mathrm{~B}_{4} \mathrm{O}_{7}$ single crystals. Sol. State Phys. 1989, 31, 275-278.

17. Wooten, D.; Ketsman, I.; Xiao, J.; Losovyj, Ya.B.; Petrosky, J.; McClory, J.; Burak, Ya.V.; Adamiv, V.T.; Dowben, P.A. The surface core level shift for lithium at the surface of lithium borate. J. Phys.-Condens. Matter 2010, 405, 461-464.

18. Wooten, D.; Ketsman, I.; Xiao, J.; Losovyj, Y.B.; Petrosky, J.; McClory, J.; Burak, Y.V.; Adamiv, V.T.; Dowben, P.A. Differences in the surface charging at the (100) and (110) surfaces of $\mathrm{Li}_{2} \mathrm{~B}_{4} \mathrm{O}_{7}$. In Nuclear Radiation Detection Materials; Perry, D.L., Burger, A., Franks, L., Yasuda, K., Fiederle, M., Eds.; Materials Research Society: Warrendale, Pennsylvania, PA, USA, 2009.

19. Swinney, M.W.; McClory, J.W.; Petrosky, J.C.; Yang, Shan; Brant, A.T.; Adamiv, V.T.; Burak, Ya.V.; Dowben, P.A.; Halliburton, L.E. Identification of electron and hole traps in lithium tetraborate $\left(\mathrm{Li}_{2} \mathrm{~B}_{4} \mathrm{O}_{7}\right)$ crystals: Oxygen vacancies and lithium vacancies. J. Appl. Phys. 2010, 107, 113715, DOI:10.1063/1.3392802

20. Feng, D.-Q.; Wisbey, D.; Losovyj, Ya.B.; Tai, Y.; Zharnikov, M.; Dowben, P.A. Electronic structure and polymerization of a self-assembled monolayer with multiple arene rings. Phys. Rev. B 2006, 74, 165425, DOI: 10.1103/PhysRevB.74.165425.

21. Smith, N.V. Inverse photoemission. Rept. Prog. Phys. 1988, 51, 1227.

22. Spanjaard, D.; Guillot, C.; Desjonquères, M.-C.; Tréglia, G.; Lecante, J. Surface core level spectroscopy of transition metals: A new tool for the determination of their surface structure. Surf. Sci. Repts. 1985, 5, 1-85.

23. Citrin, P.H.; Wertheim, G.K.; Baer, Y. Core-Level Binding Energy and Density of States from the Surface Atoms of Gold. Phys. Rev. Lett. 1978, 41, 1425-1428. 
24. Whatmore, R.W.; Shorroks, N.M.; O’Hara, C.; Alinger, F.W. Lithium tetraborate: A new temperature-compensated saw substrate material. Electron. Lett. 1981, 17, 11-12.

25. Bhalla, A.S.; Cross, L.E.; Whatmore, R.W. Pyroelectric and piezoelectric properties of lithium tetraborate single crystal. Jpn. J. Appl. Phys. 1985, 24, 727-729.

26. Burak, Ya.V. Influence of the pyroelectroluminescence for the structure investigations of the $\mathrm{Li}_{2} \mathrm{~B}_{4} \mathrm{O}_{7}$ single crystals. J. Phys. Stud. 1998, 2, 62-64.

27. Ebata, Y.; Suzuki, H.; Matsumura, S.; Fukuda, K. SAW Propagation characteristics on $\mathrm{Li}_{2} \mathrm{~B}_{4} \mathrm{O}_{7}$. Jpn. J. Appl. Phys. 1983, 22, 160-162.

28. Adachi, M.; Shiosaki, T.; Kobayashi, H.; Ohnishi, O.; Kawabata, A. Temperature compensated piezoelectric lithium tetraborate crystal for high frequency surface acoustic wave and bulk wave device applications. Proc. IEEE Ultrason. Symp. 1985, 228-232.

29. Abe, H.; Saitou, H.; Ohmura, M.; Yamada, T.; Miwa, K. Lithium Tetraborate $\left(\mathrm{Li}_{2} \mathrm{~B}_{4} \mathrm{O}_{7}\right) \mathrm{SAW}$ Resonators. Proc. IEEE Ultrason. Symp. 1987, 91-94.

30. Takeuchi, M.; Odagawa, H.; Tanaka, M.; Yamanouchi, K. Low loss surface acoustic wave filter on natural-single phase unidirectical transducter orientations of a $\mathrm{Li}_{2} \mathrm{~B}_{4} \mathrm{O}_{7}$ substrate. Jpn. J. Appl. Phys. 1997, 36, 3091-3095.

31. Shorroks, N.M.; Whatmore, R.W.; Aiger, F.M. Lithium tetraborate-A new temperature compensated piezoelectric substrate material for surface acoustic wave devices. Proc. IEEE Ultrason. Symp. 1981, 337-340.

32. Wang, J.; Zhang, L.; Qin, Z.; Wang, H.; He, D.; Ho, S. Measurement of all electro-elastic constants of lithium tetraborate $\left(\mathrm{Li}_{2} \mathrm{~B}_{4} \mathrm{O}_{7}\right)$ crystal. Chin. J. Acoustics 1990, 9, 123-128.

33. Bohaty, L.; Haussuhl, S.; Liebertz, J. Electrooptical coefficients and temperature and pressure derivatives of the elastic constants of tetragonal $\mathrm{Li}_{2} \mathrm{~B}_{4} \mathrm{O}_{7}$. Cryst. Res. Technol. 1989, 24, 1159-1163.

34. Silvestrova, I.M.; Senyuchenkov, P.A.; Lomonov, V.A.; Pisarevskii, Yu.V. The anomaly of the temperature dependence of the elastic properties of the lithium tetraborate for thermocycling. Phys. Sol. State 1989, 31, 311-313.

35. Shiosaki, T.; Adachi, M.; Kobayashi, H.; Araki, K.; Kawabata, A. Elastic, piezoelectric, acousto-optic and electro-optic properties of $\mathrm{Li}_{2} \mathrm{~B}_{4} \mathrm{O}_{7}$. Jpn. J. Appl. Phys. 1985, 24, 25-27.

36. Maeda, M.; Tachi, H.; Honda, K.; Suzuki, I. Dielectric, elastic and piezoelectric properties of $\mathrm{li}_{2} \mathrm{~b}_{4} \mathrm{O}_{7}$ single crystals in temperature range from $4 \mathrm{~K}$ to $900 \mathrm{~K}$. Jpn. J. Appl. Phys. 1994, 33, 1965-1969.

37. Sehery, A.A.; Somerford, D.J. Low-temperature elastic anomalies in lithium tetraborate. J. Phys. Cond. Matter 1989, 1, 2279.

38. Bardeen, J.; Morrison, S.R. Surface barriers and surface conductance. Physica 1954, 20, 873-884.

39. Schroder, D.K. Surface voltage and surface photovoltage: History, theory and applications. Meas. Sci. Technol. 2001, 12, R16-R31.

40. Demuth, J.E.; Thompson, W.J.; DiNardo, N.J.; Imbihl, R. Photoemission-based photovoltage probe of semiconductor surface and interface electronic structure. Phys. Rev. Lett. 1986, 56, 1408-1411. 
41. Alonso, M.; Cimino R.; Horn, K. Surface photovoltage effects in photoemission from metal-GaP(110) interfaces: Importance for band bending evaluation. Phys. Rev. Lett. 1990, 64, 1947-1950.

42. Stiles, K.; Kahn, A. Correlation between $\mathrm{E}_{\mathrm{F}}$ pinning and development of metallic character in Ag overlayers on GaAs(110). Phys. Rev. Lett. 1988, 60, 440.

43. Kim, C.-S.; Park, J.-H.; Moon, B.K.; Seo, H.-J.; Choi, B.-C.; Hwang, Y.-H.; Kim, H.K.; Kim, J.N. Conductance of surface layer in lithium tetraborate single crystals. J. Appl. Phys. 2003, 94, 7246, DOI:10.1063/1.1622774

44. Sangeeta, K.C.; Chennakesavulu, K.; Deai, D.G.; Sabharwal, S.C.; Alex, M.;

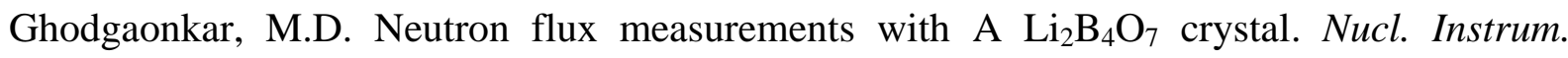
Methods Phys. Res. A 2007, 571, 699.

45. Xiao, J.; Lozova, N.; Losovyj, Ya.B.; Wooten, D.; Ketsman, I.; Swinney, M.W.; Petrosky, J.; McClory, J.; Burak, Ya.V.; Adamiv, V.T.; Brant, A.T.; Dowben, P.A. Surface charging at the (100) surface of $\mathrm{Cu}$ doped and undoped $\mathrm{Li}_{2} \mathrm{~B}_{4} \mathrm{O}_{7}$. Appl. Surf. Sci.2010, submitted.

46. Antonyak, O.T.; Adamiv, V.T.; Burak, Ya.V.; Teslyuk, I.M. Thermoluminescence of doped $\mathrm{Li}_{2} \mathrm{~B}_{4} \mathrm{O}_{7}$ single crystals. Adv. Func. Mater. 2002, 9, 452-455.

47. Coradi, C.; Nagirnyi, V.; Kotlov, A.; Watternich, A.; Kirm, M.; Polgar, K.; Hofstaetter, A.; Meyer, M. Investigation of $\mathrm{Cu}$-doped $\mathrm{Li}_{2} \mathrm{~B}_{4} \mathrm{O}_{7}$ single crystals by electron paramagnetic resonance and time resolved optical spectroscopy. DOI: 10.1088/0953-8984/20/02/025216.

48. Piwowarska, D.; Kaczmarek, S.M.; Berkowski, M.; Stefaniuk, I. Growth and EPR and optical properties of $\mathrm{Li}_{2} \mathrm{~B}_{4} \mathrm{O}_{7}$ single crystals doped with $\mathrm{Co}^{2+}$ ions. J. Cryst. Growth 2006, 291, 123-129.

49. Podgorska, D.; Kaczmarek, S.M.; Drozdowski, W.; Wabia, M.; Kwasny, M.; Warchol, S.; Rizak, V.M. Recharging processes of $\mathrm{mn}$ ions in $\mathrm{Li}_{2} \mathrm{~B}_{4} \mathrm{O}_{7}$ : Mn single crystal and glass samples under the influence of g-irradiation and annealing. Molecular Phys. Repts. 2004, 39, 199-222.

50. Burak, Ya.V.; Adamiv, V.T.; Antonyak, O.T.; Malynych, S.Z.; Pidzyrailo, M.S.; Teslyuk, I.M. Thermoluminescence in doped single crystals $\mathrm{Li}_{2} \mathrm{~B}_{4} \mathrm{O}_{7}: \mathrm{A}(\mathrm{A}=\mathrm{Cu}, \mathrm{Ag}) . U k r . J$. Phys. 2005, 50, 1153-1158.

51. Hunda, B.M.; Puga, P.P.; Solomon, A.M.; Holovey, M.I. Energetic position of the trapping centers and the temperature dependence of the X-ray luminescence of copper-doped lithium tetraborate single crystals. Ukr. J. Phys. 2000, 45, 337-341.

52. Ishii, M.; Kuwano, Y.; Asai, T.; Senguttuvan, N.; Hayashi, T.; Kobayashi, M.; Oku, T.; Sakai, K.; Adachi, T.; Shimizu, H.M.; Suzuki, J. Growth of Cu-doped $\mathrm{Li}_{2} \mathrm{~B}_{4} \mathrm{O}_{7}$ single crystals by vertical Bridgman method and their characterization. J. Cryst. Growth 2003, 257, 169-176.

53. Park, K.S.; Ahn, J.K.; Kim, D.J.; Kim, H.K.; Hwang, Y.H.; Kim, D.S.; Park, M.H.; Park, Y.; Yoon, J.J.; Leem, J.Y. Growth and properties of $\mathrm{Li}_{2} \mathrm{~B}_{4} \mathrm{O}_{7}$ single crystals doped with $\mathrm{Cu}, \mathrm{Mn}$ and Mg. J. Cryst. Growth 2003, 249, 483-486.

54. Senguttuvan, N.; Ishii, M.; Shimonova, M.; Kobayashi, M.; Tsutsui, N.; Nikl, M.; Dusek, M.; Shimizu, H.M.; Oku, T.; Adachi, T.; Sakai, K.; Suzuki, J. Crystal growth and luminescence properties of $\mathrm{Li}_{2} \mathrm{~B}_{4} \mathrm{O}_{7}$ single crystals doped with $\mathrm{Ce}$, In, Ni, $\mathrm{Cu}$ and Ti ions. Nucl. Instrum. Methods 2002, A486, 264-267. 
55. Adamiv, V.T.; Savchyn, V.P.; Savchyn, P.V.; Teslyuk, I.M.; Burak, Ya.V. Influence of isovalent doping on the cathodoluminescence of $\mathrm{Li}_{2} \mathrm{~B}_{4} \mathrm{O}_{7}$ : $\mathrm{A}(\mathrm{A}=\mathrm{K}, \mathrm{Cu}, \mathrm{Ag})$ single crystals. Functional Mat. 2009, 16, 247-252.

56. Holovey, V.M.; Sidey, V.I.; Lyamayev, V.I.; Puga, P.P. Influence of reducing annealing on the luminescent properties of $\mathrm{Li}_{2} \mathrm{~B}_{4} \mathrm{O}_{7}: \mathrm{Cu}$ crystals. J. Lumin. 2007, 126, 408-412.

57. Antonyak, O.T.; Burak, Ya.V.; Lysejko, I.T.; Pidzyrailo, M.S.; Khapko, Z.A. Luminescence of the $\mathrm{Li}_{2} \mathrm{~B}_{4} \mathrm{O}_{7}$ single crystals. Opt. Spectrosc. 1986, 61, 550-553.

58. Vinograd, E.L.; Vydai, Yu.T.; Zagarii, L.B.; Kosmyna, M.B.; Kudin, A.M.; Levin, A.B.; Nazarenko, B.N.; Tarasov, V.A.; Chernikov, V.V. Scintillation parameters lithium contain single crystals: $\mathrm{Li}_{2} \mathrm{~B}_{4} \mathrm{O}_{7}, \mathrm{LiTaO}_{3}, \mathrm{LiNbO}_{3}$. Adv. Funct. Mater. 1994, 1, 152-153.

59. Baumer, V.N.; Chernikov, V.V.; Dubovik, M.F.; Gavrylyuk, V.P.; Grinyov, B.V.; Grin, L.A.; Korshikova, A.N.; Shekhovtsov, E.P.; Sysoeva, A.V.; Tolmachev, O.V.; Zeleskaya, T.I. Comparative analysis of scintillation parameters peculiarities of $\mathrm{Li}_{2} \mathrm{~B}_{4} \mathrm{O}_{7}, \mathrm{LaB}_{3} \mathrm{O}_{6}$, $\mathrm{Li}_{6} \mathrm{Gd}\left(\mathrm{BO}_{3}\right)_{3}$ single crystals. Adv. Funct. Mater. 2001, 8, 736-741.

60. Ignatovych, M.; Holovey, V.; Vidoczy, T.; Baranyai, P.; Kelemen, A.; Laguta, V.; Chuiko, O. Spectroscopy of $\mathrm{Cu}$ - and Ag-doped single crystal and glassy lithium tetraborate: luminescence, optical absorption and ESR study. Adv. Funct. Mater. 2005, 12, 313-317.

61. Adamiv, V.T.; Antonyak, O.T.; Burak, Ya.V.; Pidzyrailo, M.S.; Tesluk, I.M. Model of $\mathrm{TSL}$ - centers in $\mathrm{Li}_{2} \mathrm{~B}_{4} \mathrm{O}_{7}: \mathrm{A}(\mathrm{A}=\mathrm{Cu}, \mathrm{Ag})$ single crystals. Adv. Funct. Mater. 2005, 12, 278-280.

62. Ogorodnikov, I.N.; Pustovarov, V.A.; Kruzhalov, A.V.; Isaenko, A.V.; Kirm, M.; Zimmerer, G. STE in $\mathrm{LiB}_{3} \mathrm{O}_{5}$ and $\mathrm{Li}_{2} \mathrm{~B}_{4} \mathrm{O}_{7}$ lithium borates. Low-temperature time-resolved luminescent VUV spectroscopy. Phys. Solid State 2000, 42, 464-472.

63. Ogorodnikov, I.N.; Yakovlev, V.Yu.; Kruzhalov, A.V.; Isaenko, A.V. Metastable optical absorption and luminescence of lithium tetraborates $\mathrm{Li}_{2} \mathrm{~B}_{4} \mathrm{O}_{7}$. Phys. Solid State 2002, 44, 1085-1083.

64. Ogorodnikov, I.N.; Pustovarov, V.A.; Kruzhalov, A.V.; Isaenko, L.I.; Kirm, M.; Zimmerer, G. A time-resolved spectroscopy study of fast luminescence in lithium borates. In Proceedings of the International Conference on Inorganic Scintillators and Their Applications-SCINT99. Mikhailin, V.V. Eds.; Moscow State University: Moscow, Russia, 16 August, 2000; pp. 242-247.

65. Nagirnyi, V.; Kotlov, A.; Corradi, G.; Watterich, A.; Kirm, M. Electronic transitions in $\mathrm{Li}_{2} \mathrm{~B}_{4} \mathrm{O}_{7}: \mathrm{Cu}$ single crystals. Phys. Stat. Sol. 2007, 4, 665-888.

66. London, D.; Zolensky, M.E.; Roedder, E. Diomignite: natural $\mathrm{Li}_{2} \mathrm{~B}_{4} \mathrm{O}_{7}$ from the tanco pegmatite, Bernic lake, Manitoba. Canad. Mineralogist. 1987, 25, 173-180.

67. Sastry, B.S.R.; Hummel, F.A. Studies in lithium oxide systems: I, $\mathrm{Li}_{2} \mathrm{O} \cdot \mathrm{B}_{2} \mathrm{O}_{3}-\mathrm{B}_{2} \mathrm{O}_{3}$. J. Am.Ceramic Soc. 1958, 41, 7-17.

68. Garrett, J.D.; Iyer, M.N.; Greedan, J.E. The czochralski growth of $\mathrm{LiBO}_{2}$ and $\mathrm{Li}_{2} \mathrm{~B}_{4} \mathrm{O}_{7}$. J. Cryst. Growth 1977, 41, 225-227.

69. Burak, Ya.V.; Adamiv, V.T.; .Teslyuk, I.M.; Shevel, V.M. Optical absorption of isotopically enriched $\mathrm{Li}_{2} \mathrm{~B}_{4} \mathrm{O}_{7}$ single crystals irradiated by thermal neutrons. Rad. Meas. 2004, 38, 681-684. 
70. Losovyj, Ya.; Ketsman, I.; Morikawa, E.; Wang, Z.; Tang, J.; Dowben, P.A. Optimization of the $3 \mathrm{~m}$ TGM beamline, at CAMD, for constant initial state spectroscopy. Nucl. Instrumen. Methods Phys. Res. A 2007, 582, 264-266.

71. Dowben, P.A.; LaGraffe, D.; Onellion, M. Final state symmetry effects in photoemission of thin Gd overlayers. J. Phys. Cond. Matt. 1989, 1, 6571-6587.

72. Hormes, J.; Scott, J.D.; Suller, V.P. The center for advanced microstructures and devices: A status report. Synchrotron Radiat. News 2006, 19, 27.

73. Kuznetsov, A.Yu.; Kruzhalov, A.V.; Ogorodnikov, I.N.; Sobolev, A.B. Electron structure of the lithium tetraborate $\mathrm{Li}_{2} \mathrm{~B}_{4} \mathrm{O}_{7}$ crystals. The cluster calculation and $\mathrm{X}$-ray photoelectron spectroscopy. Phys. Solid State 1999, 41, 48-49.

74. Kanaya, K.; Okayama, S. Penetration and energy loss theory of electron in solid targets. J. Phys. D: Appl. Phys. 1972, 5, 43-58.

75. Herbert, W.; Pasemann, L. Theoretical study of the information depth of the cathodoluminescence signal in semiconductor materials. Phys. Stat. Sol. A 1984, 85, 641-648.

76. Seidl, E.; Schwertführer, W. Lithiumborat-einkristalle als neutronendetektoren. Atomkernenergie 1966, 155-162.

(C) 2010 by the authors; licensee MDPI, Basel, Switzerland. This article is an open access article distributed under the terms and conditions of the Creative Commons Attribution license (http://creativecommons.org/licenses/by/3.0/). 